HID 43 (2016)

\title{
LA CUENTA DE MERCADERES Y LAS RENTAS MENUDAS DEL ALMOJARIFAZGO MAYOR DE SEVILLA A FINALES DEL SIGLO XV ${ }^{1}$
}

\author{
MERCHANTS' ACCOUNT AND THE PETTY CUSTOMS OF THE \\ SEVILLE ALMOJARIFAZGO MAJOR AT THE END OF THE $15^{\mathrm{TH}}$ \\ CENTURY
}

\author{
Juan Manuel Bello León \\ Instituto de Estudios Medievales y Renacentistas \\ de la Universidad de La Laguna (CEMYR) ${ }^{2}$ \\ jmbello@ull.es
}

RESUMEN: Con un fondo documental excepcional procedente de los archivos de Simancas y Real Chancillería de Valladolid que recogen la contribución de varios centenares de mercaderes al almojarifazgo mayor de Sevilla y la declaración detallada del valor de las llamadas rentas menudas de dicho almojarifazgo, en este trabajo se ofrecen nuevos datos sobre la evolución de esta renta en la ciudad de Sevilla a finales de la Edad Media.

PALABRAS ClaVE: Hacienda Real; Sevilla siglo XV; Almojarifazgo

ABSTRACT: This work offers new evidence about the evolution of custom duties in the city of Seville by the end of the Middle Ages. Its exceptional sources are located in the Simancas Record Office and in that of Valladolid Royal Chancery. The files contain the contributions issued by hundreds of merchants to the Sevillian Almojarifazgo Major rentas menudas (custom duty) and their detailed tax declaration concerning the worth of the so called "petty customs" in that particular almojarifazgo.

KEYWORDS: Royal Treasury; Seville, $15^{\text {th }}$ century; almojarifazgo.

1. "Abreviaturas utilizadas" AGS=Archivo General de Simancas; AMS = Archivo Municipal de Sevilla; ARChV = Archivo de la Real Chancillería de Valladolid; Carp. = Carpeta; Leg. = Legajo; RAH $=$ Real Academia de la Historia.

2. Este trabajo forma parte del proyecto de investigación financiado por el Ministerio de Educación y que lleva por título "Solidaridad y/o exclusión en las fronteras marítimas. Castilla en la baja Edad Media” (referencia HAR2013-48433-c2-2-p). 


\section{INTRODUCCIÓN}

Todos aquellos que alguna vez se han acercado al sistema impositivo que se fue desarrollando en el reino de Castilla desde mediados del siglo XIII han constatado que el cuadro de ingresos y gastos (señoriales, concejiles, reales) que se fue definiendo en función de las distintas actividades económicas que se generaban, presentaban una procedencia y argumento doctrinal tan enmarañado que aún hoy en día sigue siendo difícil de clarificar hasta para el investigador más experimentado. Esa realidad se manifestó, especialmente, en la actividad comercial del reino, ya que ésta se vio mediatizada por un sistema fiscal a menudo confuso, con un exceso de reglamentación las más de las veces inoperante y por un caos organizativo en la percepción de los ingresos que, al final, repercutían sobre unos recursos que teóricamente eran cuantiosos pero que en la práctica casi siempre resultaban menos productivos de lo que las instituciones esperaban. Un endémico fraude fiscal, el habitual enfrentamiento entre señores, concejos y la Corona por sus respectivos derechos y un complejo sistema de recaudación en el que participaban oficiales reales, arrendatarios y subarrendatarios no hicieron sino conformar un enrevesado sistema tributario que tardó siglos en definirse, pero que, pese a todas las dificultades, consiguió generar un modelo impositivo que, con algunas modificaciones, pervivió en el reino durante varios siglos.

La investigación sobre el desarrollo de la fiscalidad castellana, en sus vertientes institucional y cuantitativa, ha atraído la atención de los historiadores desde hace mucho tiempo. Los trabajos de Ramón Carande, Modesto Ulloa, Denis Menjot, Rosana de Andrés, José Damián González, Antonio Collantes, J. Carretero Zamora, David Alonso, Miguel A. Ladero, Pablo Ortego ${ }^{3}$ o el nutrido grupo de investigadores que se reúnen en torno a la red Arca Comunis ${ }^{4}$, han arrojado mucha luz sobre las haciendas reales, concejiles o señoriales. Desde hace años se ha progresado notablemente en el conocimiento de aspectos como la recaudación de los tributos y los diversos grupos financieros que participaron en su gestión, el volumen de los ingresos y los beneficiarios del gasto, la vinculación entre la hacienda regia y las haciendas de otras jurisdicciones (concejil, señorial y eclesiástica) o el nexo entre el desarrollo del poder monárquico en los siglos finales de la Edad Media y el paulatino control de los mecanismos de recaudación y distribución de

3. La simple enumeración de los trabajos que Miguel A. Ladero Quesada ha dedicado a los estudios de la hacienda castellana podría ser suficiente para comprender que nos encontramos ante un objeto de estudio bastante conocido. Véase Ladero Quesada, 1982, pp.7-38; 1973 (reedición de 2009); 2011. Un amplio estado de la cuestión en un reciente trabajo suyo. Véase Ladero Quesada, 2015, pp.13-54. Además de esta bibliografía de referencia, es necesario señalar que en el 2013 se presentó en la Universidad Complutense de Madrid la tesis doctoral de Pablo Ortego Rico que, tras su edición, está llamada a convertirse en una obra de referencia imprescindible para el análisis de la fiscalidad castellana en los siglos finales de la Edad Media. Véase Ortego Rico, 2015.

4. Arca Comunis es una red de proyectos de investigación, vinculado al Instituto de Estudios Fiscales, que acoge a más de cincuenta profesores e investigadores que trabajan sobre la Hacienda y Fiscalidad hispana medieval y moderna. Desde su creación han realizado varios congresos y publicado numerosos trabajos relacionados con las líneas temáticas de los proyectos que integran la red. 
las rentas. En última instancia, y como ha insistido en varias ocasiones el profesor Ladero Quesada, una parte importante de las fuentes medievales castellanas que se conservan emanaron de las instituciones fiscales, lo que nos ha permitido conocer bastante bien muchos aspectos de la historia de la Hacienda medieval castellana.

De entre todos los derechos que a lo largo de los siglos XIII a XV gravaron los intercambios comerciales, especialmente en los puertos andaluces, voy a detenerme en uno -el almojarifazgo mayor de Sevilla- que, pese a ser bien conocido por los historiadores gracias a su incidencia en el desarrollo de las actividades económica en Andalucía y por los conflictos que se generaron en torno a su administración, aún puede ofrecer datos de interés para comprender el mundo mercantil hispalense a finales de la Edad Media. Y lo voy a hacer describiendo dos aspectos de esta renta que han tenido un análisis limitado debido a que no se han dado a conocer las fuentes directas que permitirían esta tarea. Me refiero, en primer lugar, a la serie de ingresos recaudados en las llamadas rentas menudas o rentas anejas del almojarifazgo mayor y, en segundo, a la amplísima y detallada relación de mercaderes que en la Sevilla de finales del siglo XV abonaba lo que los arrendatarios les exigieron a cuenta del desarrollo de su actividad mercantil. Para ello contamos con ciertos documentos excepcionales, caso del que se halla inserto en un largo y complejo pleito que pasó por varias instancias judiciales hasta llegar a la Real Chancillería de Valladolid ${ }^{5}$. Este documento, con más de 4.000 folios, y que ya ha sido utilizado en otros trabajos ${ }^{6}$, tiene su origen en las desavenencias entre los socios de la compañía formada por Gonzalo de Segovia y Pedro del Campo a finales del siglo XV. El mayor interés de este tipo de documentación, originada a lo largo de un proceso judicial de estas características, se encuentra en que contiene una amplia información sobre los contribuyentes, distinta a la que habitualmente encontramos en las secciones que informan sobre la Hacienda Real en el Archivo General de Simancas ${ }^{7}$. A estos documentos podemos añadir -al menos de momento- otras informaciones que permiten completar la imagen de esta renta y de los mercaderes que operaron en Sevilla en la época que estamos analizando (finales del siglo XV y primeros años del XVI). Proceden de la Cámara de Castilla del citado archivo y en ellos se pueden encontrar testimonios de la "cuenta de mercaderes" y de las rentas anejas de los años 1509,1510 y 1512 , en este caso formando parte de pequeños expedientes

5. ARChV. Pleitos Civiles. Pérez Alonso (fenecidos). Cajas 102-5, 103-1 y 104-1.

6. Casado Alonso, 2000; Bello León, 2012.

7. Es sabido que en las secciones de Contaduría Mayor de Cuentas, Escribanía Mayor de Rentas, Expedientes de Hacienda, etc. es habitual encontrar documentación referida al proceso de arrendamiento de las rentas de la Corona (actas de subastas, licitaciones, recudimientos, las cuentas rendidas por los recaudadores mayores de cada partido, etc.) pero no información sobre el pago que hizo cada uno de los mercaderes ni el detalle del valor que alcanzó cada una de las imposiciones del almojarifazgo. Siempre hay excepciones y una de ellas se encuentra en otro documento también extraordinario que, en este caso, si se encuentra en el Archivo de Simancas. Se trata de la documentación contenida en el legajo n ${ }^{\circ}$ 90/1 de la Escribanía Mayor de Rentas del citado archivo. Parte de esa documentación ya fue descrita y utilizada por Aznar Vallejo. y Palenzuela Domínguez, 2009, pp. 673-689. 
en los que se da cuenta de la relación de los comerciantes que contribuyeron ese año en la citada renta ${ }^{8}$.

\section{El almojarifazgo MAYOR De SEVILla.}

En el marco de los intercambios mercantiles en Andalucía el almojarifazgo mayor de Sevilla constituye el principal gravamen aduanero que afectaba al comercio de la región, sirviendo además su legislación y aranceles de modelos para otros regímenes fiscales, como los almojarifazgos de Canarias, Indias o señoriales ${ }^{9}$. Como otras rentas de la Corona estaba formada por ingresos de carácter diverso, aunque en esencia lo principal de su recaudación lo constituía la percepción de un porcentaje sobre las mercancías cargadas y descargadas en los puertos andaluces ${ }^{10}$. En el conjunto de la Hacienda Real, el almojarifazgo (junto con la alcabala) es la renta mejor conocida del sistema fiscal castellano ${ }^{11}$ por lo que mucho de lo que aquí digamos resulta de insistir sobre su aplicación concreta a la realidad mercantil andaluza además de aportar algunas noticias que permitan ofrecer una visión más completa acerca de esta renta. En cualquier caso parece obligado hacer una pequeña aproximación a lo que se conoce sobre su origen y los problemas de su imposición y recaudación ya que con ello se puede entender mejor algunas de las cuestiones que veremos más adelante.

Todos los historiadores coinciden en que los orígenes de esta renta hay que buscarlos en la herencia fiscal legada por al-Andalus a los reinos cristianos, mientras que los trabajos de Miguel A. Ladero y Damián González han demostrado que en su composición se trataba de un conjunto de impuestos indirectos que afectaban a bienes y negocios muy heterogéneos ${ }^{12}$. Las rentas iban desde las cobradas por el uso comercial de inmuebles de propiedad regia (tiendas, alhóndigas, almacenes, etc), pasando por los diezmos de algunos productos hasta llegar a una serie de

8. AGS. Diversos de Castilla. Libro III, documento $\mathrm{n}^{\circ} 24$ y Libro IV, documentos $\mathrm{n}^{\circ} 30, \mathrm{y} \mathrm{n}^{\mathrm{o}} 107$.

9. El Almojarifazgo Mayor es una de las rentas mejor conocidas de la Hacienda castellana como lo demuestran los numerosos trabajos elaborados por González Arce o Ladero Quesada. Véanse Ladero Quesada, 1969, pp. 69 y ss.; González Arce, 1991, pp. 151-159; 1993, pp.165-196; 1997, pp. 209-254; 2012 b, pp. 99-137; 2015, pp. 2043-273. Las peculiaridades del almojarifazgo canario puede seguirse en la obra de Aznar Vallejo, 1983, pp. 121-124. Para otras localidades andaluzas véanse los trabajos de Romero Medina, R. 2009, 35-62 o el de Carriazo Rubio, 2014, pp. 193-210. Sobre el almojarifazgo de Indias véase también el trabajo de Ladero Quesada, 2008, o el de Pulido Bueno, 1993.

10. He de advertir que el almojarifazgo no afectaba sólo a las mercancías descargadas en los puertos de la región sino que, además, también se cobraba en ciudades del interior (Córdoba, Murcia, Toledo, etc.).

11. La importancia del almojarifazgo mayor en el conjunto de las rentas de la Corona queda bien reflejado en alguno de los escritos que sus arrendatarios dirigían al concejo hispalense cada vez que encontraban problemas para su percepción. Su opinión, aunque interesada, suele ser altamente positiva, calificando a ésta renta como "la mas principal de Sevilla". Véase alguno de estos escritos en AMS. Actas Capitulares. Cabildo de 27-III-1479; o Cabildo de 27-V-1501.

12. Ladero Quesada, 2011, pp. 137-151 y González Arce, 1997, pp. 209-254. La evolución y los cambios que se introdujeron en la administración del almojarifazgo mayor puede verse en la tesis doctoral de Alonso García, 2004 a. 
aranceles aduaneros con un tipo general del 5 ó 10 por 100, con algunas excepciones aplicadas a los mercaderes genoveses ${ }^{13}$. Además, se establecen algunas exenciones a favor de los productos que los vecinos de Sevilla traían para su uso personal o para aquellos objetos que se movían como consecuencia del cambio de domicilio. En cualquier caso el elemento aduanero fue cobrando cada vez mayor importancia, de tal forma que entre el siglo XIII y XV fueron suprimidos del almojarifazgo real una serie de tributos que por su escasa cuantía se fueron cediendo a los concejos y señores o bien pasaron a arrendarse por separado ${ }^{14}$. Con estos precedentes llegaba la renta al siglo XV, momento a partir del cual el almojarifazgo se arrendó en tres grandes bloques diferenciados; el "diezmo del aceite" 15 , las "rentas menudas" y el "almojarifazgo propiamente dicho".

El primero de ellos, el diezmo del aceite, constituía la única parte del diezmo de las cosechas, dentro del arzobispado hispalense, que quedó en manos de la Corona y no en las de la Iglesia, mientras que las llamadas rentas menudas eran una serie de gravámenes situados sobre algunas mercancías y su tránsito (pescado fresco y salado, lino, esparto, queso, lana, caza, etc). Más adelante veremos que la denominación de menudas no deben identificarse con un pequeño monto de tales rentas ya que entre la veintena de ingresos que se obtenían de las mismas había algunas (caso del almojarifazgo del pescado fresco o revender de los paños de oro y seda) que aportaron importantes cantidades a la Hacienda del rey. Pero es el almojarifazgo propiamente dicho y sus tres partes o denominaciones ("partido de las mercaderías", "almonaima y cuenta de mercaderes" y "renta de Berbería") ${ }^{16}$ la que formaba el núcleo principal de la renta.

Los cuadernos que fijaban las condiciones para el arrendamiento del almojarifazgo mayor, conocidos desde el reinado de Juan II, establecían los términos a los que los arrendatarios debían atenerse para la renta ${ }^{17}$. En ellos se les reconocía su derecho a tomar todas las medidas necesarias para garantizar el cobro de estos derechos y evitar con ello la merma de ingresos o un posible descuento sobre el precio del arrendamiento. En última instancia el cuaderno no hacía sino recoger

13. En diversas ocasiones los cónsules de los mercaderes genoveses acudieron al concejo hispalense para solicitar su amparo ante las pretensiones de los almojarifes que querían cobrarles el mismo arancel que a los demás. Sirva de ejemplo: A M S. Sec. $1^{\text {a }}$. Carp. 4, doc. $n^{\circ} 3$; AGS. Registro General del Sello.: 14-V-1490. f. 327 y Sanz Fuentes y Simó Rodríguez, 1975 (véase documento nº 1590, de16-X-1454).

14. No debe confundirse el Almojarifazgo Mayor o Almojarifazgo real con el Almojarifazgo que cobraba el concejo de Sevilla desde que, a mediados del siglo XIV, la Corona les traspasó las rentas del almojarifazgo de las localidades que formaban parte del alfoz hispalense. Esta renta, de la que se conserva una amplia legislación y que llegó a constituirse en una parte fundamental de sus propios, también originó numerosos enfrentamientos entre los arrendatarios, los vecinos y el concejo debido a los habituales abusos de los recaudadores y a las arbitrariedades con las que se aplicaban los aranceles recogidos en las ordenanzas y cuadernos de arrendamiento. Sobre esta cuestión véase Collantes de Terán Sánchez, 1999, pp. 463-483.

15. Sobre esta parte del almojarifazgo el profesor Damián González ha publicado un trabajo que recoge las peculiaridades de su administración y los ingresos que generaron a la Hacienda Real hasta bien entrado el siglo XVI. Véase González Arce, 2012, pp. 99-137.

16. Algunos aspectos de la renta de Berbería pueden verse en Bello León, 2006, pp. 61-76.

17. Pueden verse esa legislación en la obra de Ladero Quesada, 1999. 
los tres principales problemas que afrontaba la recaudación por parte de los almojarifes en la Baja Andalucía; a) los pleitos con el Almirante y contra los oficiales de otras instituciones (concejo y alcalde de los reales alcázares); b) la falta de control en los puertos de señorío situados en la costa atlántica; y c) el contrabando y tránsito subrepticio de mercancías que practicaban muchos vecinos de la ciudad burlando una y otra vez los controles de entrada a la misma.

Por lo demás, los cuadernos de arrendamiento preveían la forma en la que se debían tomar los distintos partidos de la renta, generalmente similares condiciones que para el arrendamiento de otros ingresos. Dada su cuantía y la complejidad del almojarifazgo mayor, fue práctica habitual el que los arrendatarios compartieran la tarea de su gestión formando auténticas compañías. Con ellas compartían las responsabilidades de su administración y, además, tenían la posibilidad de intervenir en el arriendo de otros partidos sin los riesgos de acudir a ello individualmente exponiendo todos sus bienes. Finalmente es de destacar que los reyes acogían bajo su amparo a los arrendadores del almojarifazgo mayor y a sus oficiales, autorizándoles a llevar armas aunque estuvieran vedadas en algunas villas y lugares, prohibiendo al concejo hispalense que movilizaran a los almojarifes para formar parte de alguna hueste militar o prohibiendo, también, que fueran acusados criminalmente ante alguno de los oficiales del Almirante ${ }^{18}$.

\section{Las Rentas menudas del Almojarifazgo Mayor}

La evolución, en conjunto, de los valores que alcanzaron los ingresos correspondientes al almojarifazgo mayor es conocida desde que el profesor Ladero los publicó en 1969. No ocurre lo mismo, como ya hemos dicho, con las partidas que fueron recaudadas en las rentas anejas del almojarifazgo, de las que he podido reconstruir una serie amplia correspondiente a varios años del reinado de los Reyes Católicos (véase cuadro $\mathrm{n}^{\circ} 1$ ). A grandes rasgos, el análisis de esta serie permite destacar varios aspectos.

En primer lugar, el volumen neto de tales ingresos ${ }^{19}$. Como ya dije, el hecho de que a éstas se las conozca como rentas anejas o rentas menudas no implican

18. Sobre la protección que los reyes concedían a los almojarifes véanse algunos documentos en Carande y Carriazo, 1968 (véase tomo IV, documento $\mathrm{n}^{\circ} 237$ (11-VII-1488), y tomo V, documento $\mathrm{n}^{\circ}$ 398 (17-VIII-1490). Sobre los guardas véase AGS. Registro del Sello: 31-VII-1493, f. 95; 4-V-1493, f. 93; 20-XII-1493; f. 33. AGS. Diversos de Castilla. Libro 3, documento no 105 (22-IV-1510). AMS. Tumbo de los Reyes Católicos. Tomo IV, f. 313 (31-VII-1493). Carande y Carriazo, Ob. cit. Tomo I, documento ${ }^{\circ} 89$ (25-V-1476).

19. El profesor Ladero ofrece el valor anual de esta renta entre los años 1429 y 1466 (véase Ladero Quesada, 1969, p. 77). En ellos se puede observar que la recaudación de las rentas menudas fue en aumento hasta llegar a más de un millón y medio de maravedís anuales. Comparar esas cifras de ingresos con las que ofrecemos en el cuadro $\mathrm{n}^{\circ} 1$ presenta ciertas dificultades por dos circunstancias: la primera por las fluctuaciones que sufrió la moneda castellana en el último cuarto del siglo XV y la segunda porque, como luego veremos, dentro de las rentas menudas se fueron incorporando o desapareciendo diversos gravámenes o, simplemente, no arrendaron, lo que, sin duda, repercutía en el volumen de la recaudado. 
que la cuantía de lo que se obtenía fuera desdeñable, a pesar de que valoradas en doblas de la banda ese volumen fuera disminuyendo. Para cada uno de estos años reflejados en el citado cuadro $n^{\circ} 1$ (los datos correspondientes a los años $1478-80$ son incompletos) se recaudaba entre 850.000 y 1.100 .000 maravedís. Si tenemos en cuenta que durante esos mismos años el almojarifazgo propiamente dicho recaudaba entre seis y doce millones de maravedís, el valor de estas rentas en algunos casos supone más del $13 \%$ del valor total de lo que se obtenía por el conjunto del almojarifazgo mayor.

En segundo lugar, la gran variedad de actividades y bienes que formaban parte de esta parcela de la renta. Se confirma, una vez más, que el almojarifazgo abarcaba realidades muy heterogéneas, si bien las que se recogen en el cuadro $\mathrm{n}^{\circ} 1$ están vinculadas a las actividades del mercado sevillano o al control de pesos y medidas de algunos productos. En este sentido, también he de advertir que el número de rentas que formaron parte de este grupo del almojarifazgo sufrió varios cambios en el periodo analizado. Así, desde 1488 se separa de las rentas menudas la llamado almojarifazgo del pescado salado y desaparecen de los arrendamientos el almojarifazgo de bajeles y navios, se unifican el arriendo de alguna de ellas o se incorporan otras que hasta entonces no suelen aparecer en la documentación. En este último caso se encuentran las rentas del almojarifazgo de Rota (en 1509 su valor fue de 50.300 mrs. y en 1512 de $73.500 \mathrm{mrs}$.), el de Palma (en 1509 se recaudaron 2.000 mrs.) o Chipiona (en 1509 se obtienen 70.000 mrs. y en 151273.000 mrs.). Un caso excepcional y que sólo he podido documentar en el arrendamiento de estas rentas menudas el año 1509 es la llamada alcabala de paños y fustanes de Cádiz, que en esa fecha alcanzó la notable cifra de 220.000 maravedís $^{20}$. En tercer lugar, estos ingresos también vuelven a confirmar que la actividad mercantil de Sevilla permitía obtener importantes sumas de dinero a la Corona y con ellas garantizar el pago de los títulos de deuda y atraer el interés de los financieros hacia la gestión de unas rentas que podían proporcionarles notables beneficios.

20. Dado que algunas rentas aparecen o desaparecen de los arrendamientos efectuados entre los años 1478 y 1512, en el cuadro que aquí se ofrece sólo se recogen los datos correspondientes a aquellas que se arrendaron y recaudaron de forma habitual durante ese periodo. Evidentemente eso distorsiona la suma total de lo recaudado aunque la desviación sólo es significativa para el año 1509 ya que en el cuadro no aparece la mencionada alcabala de paños y fustanes de Cádiz. 
Cuadro 1. Valor de las rentas anejas del Almojarifazgo Mayor de Sevilla (en mrs.)

\begin{tabular}{|c|c|c|c|c|c|c|c|c|}
\hline \multirow[b]{2}{*}{$\begin{array}{l}\text { DENOMINACIÓN } \\
\text { DE LA RENTA }\end{array}$} & \multicolumn{8}{|c|}{ AÑOS } \\
\hline & $\begin{array}{l}1478- \\
1480\end{array}$ & 1495 & 1496 & 1497 & 1502 & 1509 & 1510 & 1512 \\
\hline $\begin{array}{l}\text { Almojarifazgo de } \\
\text { cáñamo en pelo }\end{array}$ & --- & 30.000 & 26.000 & 26.000 & 52.525 & 75.676 & --- & 55.000 \\
\hline $\begin{array}{l}\text { Almojarifazgo del } \\
\text { lino y esparto }\end{array}$ & 46.000 & 47.457 & 56.455 & 51.455 & 73.535 & 70.000 & 80.000 & 100.000 \\
\hline $\begin{array}{l}\text { Revender de los } \\
\text { paños de oro y } \\
\text { seda }\end{array}$ & --- & 107.000 & 133.333 & 95.000 & 136.565 & 130.000 & 130.000 & \begin{tabular}{|l}
172.000 \\
\end{tabular} \\
\hline $\begin{array}{l}\text { La renta del sebo } \\
\text { y unto }\end{array}$ & --- & 25.700 & 26.400 & 28.600 & --- & --- & --- & 40.000 \\
\hline $\begin{array}{l}\text { Almojarifazgo de } \\
\text { peros y nueces }\end{array}$ & 8.500 & 10.100 & 11.500 & 11.500 & 12.606 & --- & --- & --- \\
\hline $\begin{array}{l}\text { Revender de la } \\
\text { seda y cadarzo }\end{array}$ & --- & 60.500 & 56.400 & 60.400 & 94.545 & 97.000 & 85.000 & 157.088 \\
\hline $\begin{array}{l}\text { Revender de los } \\
\text { paños y varas }\end{array}$ & --- & 160.000 & 143.600 & 144.100 & 173.333 & 125.000 & 120.000 & 200.000 \\
\hline $\begin{array}{l}\text { Revender el } \\
\text { hierro y metal }\end{array}$ & --- & 55.350 & 46.800 & 46.800 & 50.424 & 44.000 & 37.000 & 55.000 \\
\hline $\begin{array}{l}\text { Renta de revender } \\
\text { la especiería }\end{array}$ & --- & 61.100 & 65.000 & 61.000 & 54.626 & 62.000 & 70.000 & 105.500 \\
\hline $\begin{array}{l}\text { Renta de revender } \\
\text { haces y alcotonías }\end{array}$ & --- & 2.625 & 3.125 & 3.225 & 3.000 & --- & --- & 3.000 \\
\hline $\begin{array}{l}\text { Diezmo de higos } \\
\text { y aceitunas del } \\
\text { Aljarafe }\end{array}$ & --- & 4.600 & 7.000 & 8.875 & 12.006 & 8.000 & 10.000 & 14.000 \\
\hline $\begin{array}{l}\text { Almojarifazgo de } \\
\text { aves y caza }\end{array}$ & --- & 20.110 & 25.400 & 15.400 & 12.600 & 7.000 & 7.000 & 16.887 \\
\hline $\begin{array}{l}\text { Diezmo del aceite } \\
\text { que entra por las } \\
\text { puertas }\end{array}$ & --- & 22.000 & 23.860 & 23.860 & 25.000 & 25.000 & 30.000 & 40.000 \\
\hline $\begin{array}{l}\text { El terzuelo de } \\
\text { miel y cera y } \\
\text { grana }\end{array}$ & 30.050 & 26.400 & 32.400 & 32.400 & 49.333 & 31.300 & 40.000 & 45.100 \\
\hline $\begin{array}{l}\text { Almojarifazgo del } \\
\text { pescado fresco }\end{array}$ & 202.000 & 242.000 & 214.412 & 218.412 & 217.710 & 220.000 & 185.000 & 200.000 \\
\hline $\begin{array}{l}\text { Almojarifazgo de } \\
\text { la salvagina }\end{array}$ & --- & 5.740 & 8.200 & 8.200 & 21.010 & --- & --- & --- \\
\hline
\end{tabular}




\begin{tabular}{|l|c|c|c|c|c|c|c|c|}
\hline \multirow{2}{*}{$\begin{array}{l}\text { DENOMINACIÓN } \\
\text { DE LA RENTA }\end{array}$} & $\begin{array}{l}1478- \\
1480\end{array}$ & 1495 & 1496 & 1497 & 1502 & 1509 & 1510 & 1512 \\
\cline { 2 - 9 } $\begin{array}{l}\text { Las medidas del } \\
\text { aceite }\end{array}$ & 50.000 & 53.400 & 15.000 & 17.000 & 27.333 & 56.000 & 28.455 & 50.000 \\
\hline $\begin{array}{l}\text { Renta de la } \\
\text { alcabala de cueros } \\
\text { al pelo }\end{array}$ & --- & 76.000 & 94.400 & 10.6800 & --- & --- & --- & 20.6000 \\
\hline $\begin{array}{l}\text { Alcabala de frisas } \\
\text { y paños }\end{array}$ & --- & 43.000 & 46.000 & 41.000 & 57.987 & 11.000 & 10.000 & 12.000 \\
\hline $\begin{array}{l}\text { Renta de la } \\
\text { cinquena de la } \\
\text { fruta }\end{array}$ & 15.020 & 12.800 & 16.550 & 16.550 & 18.909 & 18.000 & 21.000 & 33.500 \\
\hline $\begin{array}{l}\text { Renta de las } \\
\text { libretas de } \\
\text { algodón }\end{array}$ & --- & 1.560 & 2.300 & 2.300 & --- & --- & --- & --- \\
\hline \begin{tabular}{l} 
Terçuelo de çeja \\
\hline
\end{tabular} & --- & 1.500 & --- & --- & -- & --- & -- & - \\
\hline
\end{tabular}

Nota: En los años 1509 y 1512 las rentas del lino y esparto se arrendaron junto con la de peros y nueces Fuente: AGS. Cámara de Castilla, Diversos, leg.4, doc. $n^{\circ} 30$ y doc. $n^{\circ} 31$; Leg. 3, doc. $n^{\circ} 24$; Expedientes de Hacienda, leg. 10; Escribanía Mayor de Rentas, leg. nº 90/1 y ARChV. Pleitos Civiles. Pérez Alonso (fenecidos). Cajas 102-5, 103-1 y 104-1.

Si ordenamos estas rentas menudas en función del valor que alcanza cada una de ellas también podremos deducir algunos hechos relevantes sobre esta parte del almojarifazgo mayor. Así, se puede observar que tres rentas (una se ocupa del pescado fresco y las otras dos de la venta de productos textiles) recaudan casi el 50\% de lo que se obtenía por el conjunto de las rentas menudas. Por su parte, cada año el almojarifazgo del pescado fresco era la que ingresaba la mayor cantidad (anualmente entre el 19 y el 23\% del conjunto de las rentas menudas). Esta circunstancia no es extraña si tenemos en cuenta que Sevilla actuaba como centro redistribuidor de las capturas efectuadas en el Guadalquivir y en los caladeros atlánticos. Así lo demuestra la abundante documentación que sitúa gran volumen de sardinas, congrios, sábalos o atunes vendiéndose en el mercado sevillano, así como las numerosas normas recogidas en las ordenanzas de Sevilla que determinaban los establecimientos dedicados a distribuir y fiscalizar el abasto de pescado, señalaban las calles o plazas donde comprar o vender, se preocupaban preferentemente del control de pesos y medidas o fijaban la hora -antes de las primeras horas de la mañana- en las que se podían comprar las capturas ${ }^{21}$.

21. Todos estos aspectos pueden verse en Bello León, 2007. Además del almojarifazgo del pescado fresco existía, como ya se ha dicho, un almojarifazgo del pescado salado que, desde 1488, no formaba parte de las rentas menudas. El valor que alcanzó ese almojarifazgo (entre 1490 y 1504 superaba anualmente el medio millón de maravedís) ha sido estudiado por Ladero Quesada, pp. 7-38. 
Finalmente, y en relación con las rentas menudas, también se conocen los arrendatarios de esta parte del almojarifazgo para algunos de los periodos que aquí estamos tratando. Si tomamos como ejemplo los correspondientes al año 1509 (véase tabla $n^{0} 1$ del anexo) $)^{22}$ observamos que, tal y como sucedía con otros partidos del almojarifazgo, se cumplen dos características comunes entre los financieros que asumieron la recaudación de la renta. Por un lado, todos ellos eran de origen andaluz, generalmente sevillanos, lo que es habitual si tenemos en cuenta que el arrendador solía ser una persona que conocía bien los problemas que generaba la administración de la renta y que contaba con la mínima infraestructura para garantizar su gestión. Y todo eso, como es lógico suponer, se lo proporcionaba de forma privilegiada su vecindad en la ciudad hispalense. Por el otro, la escasa cuantía de muchas de aquellas rentas menudas propició la concurrencia de un elevado número de arrendatarios, lo que llevó a que, prácticamente cada una de ellas tuviera su propio arrendador. Sólo hay una excepción en este año 1509, la del arrendador del almojarifazgo del pescado fresco, Francisco Fernández, corredor de lonja, que además de asumir la mayor cuantía de este partido también obtuvo la del revender de las especias, otra de las rentas importantes del almojarifazgo ${ }^{23}$.

\section{LA CUENTA DE MERCADERES}

La "quenta de mercaderes e almonayma" es, como ya se ha dicho, uno de las partes en las que se dividió la recaudación del almojarifazgo mayor de Sevilla desde, al menos, los comienzos del siglo XV. La definición de ambos términos parece que no presenta dificultades en el caso del primero, ya que el mismo alude a la contribución que hacía cada mercader en función del volumen de sus negocios. El segundo concepto, almonaima, es más difícil de valorar. En castellano aún conservamos varias palabras (almonas, almotacén, almoraima, etc.) que aluden a las actividades comerciales y de depósito de mercancías que se aproximan a lo que seguramente fue la almonaima. Parece que la forma en la que se recaudaba esta renta -casi siempre el arrendador rendía mensualmente cuenta de ellas- reflejan el cobro que se hacía en la aduana de todo aquello que se cargaba y descargaba a través de ella. En ese momento se aplicaría el arancel promulgado en 1491 que establecía el pago de un 5\% o un 10\% -en función de la mercancía- que entraba o salía del arzobispado de Sevilla. Habitualmente se arrendó esta parte del almojarifazgo mayor de forma conjunta - casi siempre a la "vuelta de la renta de las alcabalas del partido de las mercadería y renta de Berbería"- con las condicio-

22. Además de la tabla que se ofrece en el anexo $n^{\circ} 1$ también se conocen los arrendadores para otros periodos, como, por ejemplo, los años 1450-1456 (véase AGS. Escribanía Mayor de Rentas, leg. no 4; los años 1478-1480 (AGS. Expedientes de Hacienda, leg. nº 10) o 1510 (AGS. Diversos de Castilla, leg. $n^{\circ} 4$, documento $\left.n^{\circ} 31\right)$.

23. La figura del arrendador de las rentas reales en la Corona de Castilla está siendo profundamente revisado en los últimos años gracias a los trabajos, entre otros de Alonso García, 2004 y 2007, Carvajal de la Vega, 2010, Ortega Cera, 2010, García Fernández, (coord..) 2012 u Ortego Rico, 2015. 
nes generales que se conocen desde mediados del siglo $\mathrm{XV}$, aunque en algunos casos - como ocurrió en el periodo de 1444-49 y entre 1461-66- los cuadernos de arrendamiento detallan algunas especificidades para la recaudación de esta renta ${ }^{24}$.

La documentación hasta ahora publicada no permitía valorar el volumen de los ingresos que generaba esta parte de la renta - de la almonaima- ya que, como he dicho, los contadores o los escribanos de la Hacienda Real solían limitarse a consignar en la documentación por ellos generada el monto global. Sin embargo, con la documentación manejada en este trabajo he podido reconstruir la evolución mensual de estos ingresos para varios años de finales del siglo XV y comienzos del XVI (cuadro $\mathrm{n}^{\circ} 2$ ). A partir de los datos del cuadro $\mathrm{n}^{\circ} 2$ se observan dos fenómenos. Primero que lo recaudado en la aduana suponía - para todos estos añosmás de la mitad de la cuantía este partido. Segundo, que no parece que hubiera grandes diferencias estacionales en la cuantía de esos ingresos generados por la almonaima y, por tanto, en el movimiento de mercancías, salvo en los meses del verano de 1502, circunstancia que sólo puede explicarse por las dificultades por las que pudo atravesar la economía hispalense a causa de la reactivación de la guerra contra Francia por el dominio del Rosellón.

Cuadro 2. Almonaima del Almojarifazgo Mayor de Sevilla (en mrs.).

\begin{tabular}{|l|r|r|r|r|r|}
\hline \multirow{2}{*}{ R E C A U D A C I Ó N } & \multicolumn{5}{|c|}{ AÑOS } \\
\cline { 2 - 6 } MENSUAL & 1495 & 1496 & 1497 & \multicolumn{1}{c|}{1502} & \multicolumn{1}{c|}{1510} \\
\hline Enero & 105.412 & 157.051 & 154.786 & 239.783 & 261.619 \\
\hline Febrero & 203.267 & 166.863 & 126.400 & 269.890 & 80.346 \\
\hline Marzo & 158.147 & 196.246 & 151.273 & 226.271 & 228.420 \\
\hline Abril & 199.750 & 146.037 & 174.115 & 235.244 & 261.716 \\
\hline Mayo & 132.805 & 132.690 & 170.520 & 288.353 & 272.376 \\
\hline Junio & 225.358 & 189.533 & 162.350 & 191.239 & 260.319 \\
\hline Julio & 203.939 & 167.350 & 156.295 & 89.776 & 268.942 \\
\hline Agosto & 169.018 & 141.853 & 170.502 & 86.404 & 245.374 \\
\hline Septiembre & 227.186 & 191.912 & 195.890 & 87.455 & 221.286 \\
\hline Octubre & 252.105 & 290.385 & 286.096 & 127.264 & 224.259 \\
\hline Noviembre & 175.610 & 186.291 & 234.835 & 100.467 & 227.330 \\
\hline Diciembre & 116.405 & 174.110 & 164.761 & 165.374 & 287.963 \\
\hline Total & 2.169 .002 & 2.140 .321 & 2.147 .823 & 2.107 .520 & 2.839 .950 \\
\hline
\end{tabular}

24. Véase A G S. Escribanía Mayor de Rentas, leg. nº 2, folios 44 y 63. 
Por lo que toca a la cuenta de mercaderes, cuando en 1969 el profesor Ladero publicó el tantas veces mencionado artículo "Almojarifazgo sevillano..." ya advertía de la importancia de toda la documentación que se generó en torno a la administración de esta renta para conocer a los comerciantes - extranjeros y castellanos- que operaban en la ciudad de Sevilla a finales de la Edad Media. Desde entonces nuestro conocimiento sobre las comunidades mercantiles presentes en la ciudad en aquellos momentos se ha visto multiplicado de forma casi exponencial, de tal manera que hoy disponemos de un repertorio de fuentes y estudios relacionados con ellos muy amplia ${ }^{25}$. No obstante, para discernir un poco mejor quiénes fueron los mercaderes en la Sevilla de finales de la Edad Media contamos con la amplia nómina de aquellos que, de forma más o menos continuada, contribuyeron a la cuenta de mercaderes del almojarifazgo mayor en los años 1495 a 1497, 1502 y $1510^{26}$.

Si observamos el cuadro $n^{\circ} 3$ y las tablas del anexo (tablas $n^{\circ} 2$ y 3 ) se pueden extraer -de nuevo brevemente- algunas impresiones. En primer lugar, aún admitiendo que los almojarifes eran conscientes del enorme volumen de mercancías que escapaban a su control, también debemos suponer que los recaudadores y los guardas eran capaces de reconocer, entre la sociedad hispalense, a aquéllos que ejercían con regularidad la actividad mercantil. Por ello, las nóminas que se ofrecen en el anexo, además de identificarnos a todos ellos, nos permite aproximarnos al número real de los que ejercían en la ciudad de forma habitual el comercio y reconocer, además, a un conjunto de individuos que por la cuantía de sus pagos a los almojarifes queda evidenciado que nos encontramos ante la élite mercantil de la ciudad.

En segundo lugar, sobre el número y origen de los comerciantes registrados. En el primer caso, y para los años conocidos, la nómina fluctuó entre los 100 ó 150 inscritos, actuando la mayoría de ellos de forma individual. El origen de muchos de esos mercaderes puede ser establecido fácilmente porque a día de hoy sus nombres o actividades son perfectamente reconocibles al compararlos con la bibliografía disponible o con otras fuentes documentales ${ }^{27}$. En este sentido, una de las cuestiones que se vuelve a confirmar con estas nóminas es el importante papel

25. Los estudios dedicados a los mercaderes establecidos en Sevilla y su región son tan amplios que difícilmente pueden sintetizarse en una nota a pie de página. Los trabajos de Enrique Otte, Antonio Collantes, Ramón Carande, Hipólito Sopranis, Antonio Bernal, Miguel A. Ladero, Eduardo Aznar, etc. son una buena muestra de todo ello. He tratado de ofrecer un panorama general en Bello León, 2012.

26. Con la documentación notarial o con otro tipo de fuentes no siempre es posible seguir la evolución y estabilidad del número de comerciantes avecindados en Sevilla. La documentación de la cuenta de mercaderes permite acotar el grupo, distinguiendo a aquellos que desarrollaron una actividad constante -lo que sin duda les permitió insertarse en redes nacionales e internacionales del comercio- de aquellos otros que de forma puntual dieron cabida en sus vidas a algún tipo de intercambio mercantil.

27. He de advertir que son muy pocos los que, en la documentación original, indican su origen por lo que, para su identificación he recurrido a otras fuentes -básicamente a los protocolos notariales hispalenses- y a la bibliografía existente. Siguiendo este sistema he podido identificar el origen o la profesión de 215 individuos (sobre un total de 383 registrados), es decir, aproximadamente el 56\% de ellos. 
comercial que jugaron las comunidades de otras regiones de Castilla que se sintieron atraídos por las especiales características de Sevilla y su tierra. Un número importante de vizcaínos, gallegos y burgaleses contaban con recursos y medios equiparables a los que poseían algunos miembros de las colonias extranjeras, además de contar con su mayor integración en la sociedad hispalense y con unos estrechos vínculos familiares y comerciales con el resto de su parentela castellana ${ }^{28}$. Unido a ésta circunstancia también se encuentra el heterogéneo origen social y profesional de los que contribuyeron a la cuenta de mercaderes. Así, hallamos desde la participación de varias mujeres ${ }^{29}$ hasta miembros de la nobleza, pasando por la de representantes de oficios textiles, de la administración municipal o real, incluidos varios almojarifes. La nómina no hace sino confirmar lo que ya intuíamos por los protocolos notariales sevillanos, donde son numerosos los documentos en los que sederos, traperos, especieros, transportistas, etc. fletaban navíos, constituían asociaciones mercantiles, concedían préstamos marítimos o trabajaban con reconocidos mercaderes dedicados al comercio internacional. En definitiva, por su origen, por su capacidad inversora, por sus propiedades o por sus vínculos familiares, en Sevilla la gama de personas ligadas al comercio era tan amplia que no siempre es posible definir las líneas que separan a cada uno de ellos ${ }^{30}$.

Por otro lado, acerca de la propia evolución de la cuenta de mercaderes-sacando de ella la almonaima - dentro del almojarifazgo mayor. Como ya he dicho, los datos que en su día aportó el profesor Ladero ofrecen la suma total de almonaima y cuenta de mercaderes, por lo que no es posible conocer cuál es el porcentaje de cada uno de estos capítulos en el conjunto del almojarifazgo mayor. De nuevo, para los años en los que sí disponemos del desglose de ambas rentas los documentos parecen indicar que, pese al progresivo aumento en el número de contribuyentes, el volumen porcentual de la cuenta de mercaderes dentro del conjunto del almojarifazgo mayor se había reducido a comienzos del siglo $\mathrm{XVI}^{31}$.

28. Basta con decir que entre los diez mayores contribuyentes a la cuenta de mercaderes a finales del siglo XV se encuentran cuatro burgaleses, aunque también es sorprendente que no aparezca entre ellos Juan de Nájera, factor de los Pardo en Sevilla, también considerado como uno de los grandes mercaderes del Arlanzón afincados en la ciudad.

29. Las cuentas de mercaderes que se ofrecen en el anexo registran casi una decena de mujeres que declaran el correspondiente pago a la citada renta. Son los casos de $\mathrm{D}^{\mathrm{a}}$. Catalina de Ribera, $\mathrm{D}^{\mathrm{a}}$. Elvira Nárváez, la duquesa de Medina Sidonia, la marquesa de Montemayor, Isabel Martínez, viuda, la mujer de Alonso de Masco, Inés Peraza (seguramente una de las titulares del señorío de Canarias) y $\mathrm{D}^{\mathrm{a}}$. Isabel de Ayala.

30. Todas estas circunstancias quedan perfectamente demostradas en dos monografías de Enrique Otte Sander que vieron la luz casi al final de su vida profesional, después de cuarenta años de trabajo en los archivos notariales hispalenses. Véase Otte Sander, 1977 y 2008.

31. También es probable que ese descenso fuera coyuntural. De momento no dispongo de más datos para los primeros años del siglo XV que me permitan saber como evolucionaron ambos conceptos en el seno del almojarifazgo mayor. 
Cuadro 3. Porcentaje de la cuenta de mercaderes y almonaima sobre el total del almojarifazgo mayor de Sevilla

\begin{tabular}{|r|r|c|c|}
\hline \multicolumn{1}{|c|}{ AÑOS } & $\begin{array}{c}\text { TOTAL } \\
\text { ALMOJARIFAZGO }\end{array}$ & $\begin{array}{c}\text { CUENTA } \\
\text { MERCADERES Y } \\
\text { ALMONAIMA }\end{array}$ & $\begin{array}{c}\text { PORCENTAJE SOBRE } \\
\text { EL TOTAL DEL } \\
\text { ALMOJARIFAZGO }\end{array}$ \\
\hline $1428-33$ & $3.480 .000 \mathrm{mrs}$. & $1.500 .000 \mathrm{mrs}$. & $43,1 \%$ \\
\hline $1444-49$ & $3.309 .422 \mathrm{mrs}$. & $1.388 .552 \mathrm{mrs}$. & $41,9 \%$ \\
\hline $1450-54$ & $3.653 .835 \mathrm{mrs}$. & $1.450 .676 \mathrm{mrs}$. & $39,7 \%$ \\
\hline 1455 & $4.458 .676 \mathrm{mrs}$. & $1.950 .676 \mathrm{mrs}$. & $43,7 \%$ \\
\hline $1456-60$ & $4.938 .676 \mathrm{mrs}$. & $2.190 .676 \mathrm{mrs}$. & $44,3 \%$ \\
\hline $1461-66$ & $7.160 .000 \mathrm{mrs}$. & $3.100 .000 \mathrm{mrs}$. & $43,2 \%$ \\
\hline 1495 & $7.666 .500 \mathrm{mrs}$. & $3.952 .755 \mathrm{mrs}$. & $51,5 \%$ \\
\hline 1496 & $7.666 .500 \mathrm{mrs}$. & $3.987 .103 \mathrm{mrs}$. & $52 \%$ \\
\hline 1497 & $7.666 .500 \mathrm{mrs}$. & $4.684 .304 \mathrm{mrs}$. & $61,1 \%$ \\
\hline 1502 & $12.117 .964 \mathrm{mrs}$. & $4.823 .532 \mathrm{mrs}$. & $39,8 \%$ \\
\hline
\end{tabular}

Fuente: Ladero Quesada, M. A. La Hacienda Real castellana...Ob. cit. p. 144; ARChV. Pleitos Civiles. Pérez Alonso (fenecidos). Cajas 102-5, 103-1 y 104-1. AGS. Escribanía Mayor de Rentas, leg. $n^{\circ}$ 90/1.

Y en un tercer lugar, se observa la acusada diferencia existente entre la cuenta aportada por los mayores contribuyentes y el resto de los mercaderes que tributaban (véase tabla $\mathrm{n}^{\mathrm{o}} 1 \mathrm{del}$ anexo). He dividido el monto total de la contribución de cada uno en tramos de 10.000 maravedís y lo que se observa es que un colectivo de 15 ó 20 individuos copaban el pago de más del $80 \%$ de lo recaudado. Frente a ellos el casi centenar de mercaderes consignados que cada año de los estudiados aportaban comparativamente cantidades mucho menores a la recaudación ${ }^{32}$. Pero es que, además, dentro del colectivo de mayores contribuyentes existían notables diferencias, de tal forma que uno o dos esos mercaderes -notablemente los Pinelo o los Riberol- proporcionan hasta el $14 \%$ del total de la cuenta. Lo que conocemos de ellos por otras fuentes y por estos datos fiscales confirman, pues, que nos encontramos ante mercaderes extraordinariamente capacitados para comprar, vender o invertir en cualquier tipo de negocios. Sin olvidar que su potencia económica les permitía ejercer gran influencia sobre las condiciones en las que se desarrollaba el mercado hispalense.

Por último, los datos numéricos también permiten corroboran la preeminencia fiscal de las comunidades extranjeras en la ciudad. La presencia de 62 extranjeros -fundamentalmente genoveses-identificados en las nóminas que he maneja-

32. Es significativo que, por ejemplo en 1495, ochenta y un mercaderes aporten el $13 \%$ de lo recaudado y tan sólo dos alcancen esa misma cifra en el conjunto de lo tributado ese año. 
do demuestra que, al menos para los últimos años del siglo XV -no en 1502 ni en 1510 - los italianos fueron los mayores contribuyentes a la cuenta. Entre ellos destaca uno de los mercaderes mejor conocido -y también uno de los más influyentes- de cuantos vivieron en la Sevilla de finales de la Edad Media. Me refiero a Francisco Riberol (Francesco Ripparolio) ${ }^{33}$ y al conjunto de su amplia familia, compuesta por sus hermanos Gianotto y Cosme, su hijo Bartolomé, sus primos Bautista y Agustín o su yerno Juan Leardo. Así mismo, destaca también las contribuciones efectuadas por los Grimaldo o por los Vicencio y por Sebastián Doria. No obstante, también hay que subrayar que en estas mismas nóminas no aparecen otros dos comerciantes italianos - bien conocidos por la historiografía- como son Gaspar Centurione o Francisco Pinelo, de los que se conoce la incidencia de sus intereses en el tráfico sevillano ${ }^{34}$.

\section{CONSIDERACIONES FINALES}

La historiografía hispana y, en general europea, conoce desde hace mucho tiempo que el desarrollo de la actividad comercial que experimentó Andalucía a lo largo del siglo XV se potenció por la presencia de un importante colectivo de comerciantes, tanto castellanos como foráneos. Las consecuencias de su actividad también son conocidas: creación de toda una actividad industrial subsidiaria del comercio (toneleros, transportistas, barqueros, etc.), de instituciones que lo controlaban (almirantes, aduanas, etc.) de infraestructuras (atarazanas, muelles, navíos, etc.) y, sin duda, de un aspecto cosmopolita, especialmente en ciudades como Sevilla o Jerez. A todo esto hay que añadirle dos aspectos también notables. Por un lado, que la actividad comercial generó una inyección enorme de capitales y de negocios de compraventa en la Andalucía atlántica. Por otro, que toda esta actividad tuvo su reflejo en los ingresos percibidos por la Corona ya que la Hacienda Real, consolidando una tendencia que se venía manifestando desde principios del siglo XV, situó sobre el tráfico mercantil el máximo control que pudo alcanzar con el fin de detraer de esos intercambios el mayor beneficio posible. Creo que, de alguna forma, todo esto se refleja bien en el breve análisis que he realizado de las dos partes del almojarifazgo mayor que aquí se han considerado: las rentas menudas y la cuenta de mercaderes.

Sobre la primera de ellas, reiterar que, aunque por separado cada uno de aquellos derechos alcanzaba una escasa cuantía - a excepción del almojarifazgo del pescado fresco- el conjunto proporcionaba a la Corona la apreciable suma de más

33. Puede verse un panorama general sobre la biografía y actividades económicas de este mercader en Bello León, 2005, pp. 123-143.

34. El hecho de que no aparezcan en estas nóminas estos u otros mercaderes que conocemos por los protocolos notariales puede deberse a varios motivos. En primer lugar, porque quizás no operaban en los años aquí registrados. También pudo suceder que negociasen a través de factores o representantes y que fueran éstos quienes se encargaran de pagar la renta, o, finalmente que gozasen de algún privilegio -que desconozco- que les eximía del pago de la renta. 
de un millón de maravedís a finales del siglo XV. Sin duda, los cambios introducidos en la gestión de estas rentas -como desgajar de ella el almojarifazgo del pescado salado-y el hecho de que algunos años parte de ellas -como en 1478-80 o en 1509- no fueran arrendadas, repercutió en unos ingresos que, en general, se mantuvieron estables desde mediados de la centuria.

En cuanto a la cuenta de mercaderes, además de documentar a un número considerable de miembros de la comunidad mercantil sevillana y el diferenciado peso económico de algunos de ellos respecto al conjunto de los consignados, este tipo de documentos permite abordar la presencia en Sevilla de muchos y notables miembros de redes mercantiles nacionales e internacionales. De hecho, no es extraño que en las nóminas sea habitual encontrar a varios miembros de una misma familia de comerciantes declarando contribución a la renta. Es cierto que es más difícil cuantificar el volumen real de mercancías y beneficios obtenidos por estos mercaderes, aunque los indicios que se ofrecen estos testimonios permiten suponer que algunos mercaderes mantuvieron una actividad prolongada y muy lucrativa durante muchos años.

Por otra parte, esta documentación demuestra una vez más la enorme concurrencia social a las actividades comerciales que generaba por el polo sevillano. Grandes mercaderes extranjeros e importantes negociantes castellanos junto a gran parte del tejido social hispalense, donde los oficios manuales, la gente menuda o los miembros de la aristocracia-caballeros veinticuatro o grandes señores del reino- conforman la dinámica económica que explica el predominio social, cultural y político de Sevilla en los albores de la expansión americana.

Por último, me gustaría llamar la atención sobre un hecho que pudiera parecer contradictorio con lo que afirmamos al principio al asegurar que esta renta se veía muy afectada por el fraude que se daba entre los contribuyentes. Pues bien, el detalle en la gestión administrativa del almojarifazgo, pese al fraude, llegó hasta el punto de controlar la actividad mercantil de personas que movían un muy reducido volumen de negocio (apenas unos pocos centenares de maravedís). El hecho parece ser una muestra del celo y organización de los arrendatarios y guardas, muchos de los cuales eran también mercaderes y financieros. 


\begin{tabular}{|l|l|r|r|}
\hline \multicolumn{1}{|c|}{ DENOMINACIÓN DE LA RENTA } & \multicolumn{1}{|c|}{ ARRENDADOR } & VALOR & PROMETIDO \\
\hline Almojarifazgo de cáñamo en pelo & Diego de Medina, borceguinero, vecino Sevilla & 75.676 & 5.000 \\
\hline Almojarifazgo del lino y esparto & Pedro Hernández y Hernán González del Prado, hacedores de la aduana & 70.000 & 10.000 \\
\hline Revender de los paños de oro y seda & Andrés Barrasa & 130.000 & 5.000 \\
\hline Revender de la seda y cadarzo & Pedro Hernánez, vecino Sevilla & 97.000 & 50.000 \\
\hline Revender de los paños y varas & Hernándo Dávila, vecino Sevilla & 125.000 & 5.000 \\
\hline Revender el hierro y metal & Alonso de Londres, portero, vecino Sevilla & 44.000 & 3.000 \\
\hline Renta de revender la especiería & Francisco Fernández, corredor de lonja & 62.000 & 1.000 \\
\hline Diezmo de higos y aceitunas del Aljarafe & Juan Cuero, vecino de Sevilla & 8.000 & 1.000 \\
\hline Almojarifazgo de aves y caza & Sebastián Márquez & 7.000 & 500 \\
\hline Diezmo del aceite que entra por las puertas & Alonso de Vergara, jurado, vecino Sevilla & 25.000 & \\
\hline El terzuelo de miel y cera y grana & Hernando Baeza y Luís Hurtado & 39.300 & 0 \\
\hline Almojarifazgo del pescado fresco & Francisco Fernández, vecino Sevilla & 220.000 & 3.000 \\
\hline Las medidas del aceite & Juan de Ayala, vecino de Sevilla & 56.000 & 7.500 \\
\hline Alcabala de frisas y paños & Pedro Fernández de Sevilla, hacedor de la aduana & 3.000 \\
\hline Renta de la cinquena de la fruta & Diego de Tarifa, vecino de Sevilla & 11.000 & 1.000 \\
\hline Almojarifazgo de la villa de Rota & Alonso de Alcocer & 18.000 & 3.000 \\
\hline Almojarifazgo de palma y cogollo & Hernán Rodríguez, vecino de Sevilla & 50.300 & \\
\hline Cargo y descargo de Gibraltar & Francisco de Herrera, vecino Gibraltar & 2.000 & 0 \\
\hline Alcabala paños y fustanes de Cádiz & Gonzalo de Ribera & 20.000 & 0 \\
\hline Almojarifazgo de Chipiona & Hernando Díaz, vecino de Chipiona & 220.000 & 7.000 \\
\hline & & 70.000 & 0 \\
\hline
\end{tabular}




\begin{tabular}{|c|c|c|c|c|c|c|c|c|c|c|c|c|c|c|c|c|c|c|c|c|}
\hline \multicolumn{2}{|c|}{ PAGOS EN MRS. } & \multicolumn{3}{|c|}{ AÑO 1495} & \multicolumn{4}{|c|}{ AÑO 1496} & \multicolumn{4}{|c|}{ AÑO 1497} & \multicolumn{4}{|c|}{ AÑO 1502} & \multicolumn{4}{|c|}{ AÑO 1510} \\
\hline Entre: & mer. & $\%$ & mrs. & $\%$ & mer. & $\%$ & mrs. & $\%$ & mer. & $\%$ & mrs. & $\%$ & mer & $\%$ & mrs. & $\%$ & mer & $\%$ & mrs. & $\%$ \\
\hline $1-10.000 \mathrm{mrs}$. & 81 & 64,2 & 244.554 & 13,7 & 58 & 62,3 & 195.835 & 10,6 & 42 & 43,7 & 153.319 & 6 & 98 & 58,6 & 342.519 & 13 & 30 & 35,2 & 137.706 & 3,9 \\
\hline $10.000-20.000$ & 13 & 10,3 & 206.684 & 11,5 & 11 & 11,8 & 153.438 & 8,3 & 16 & 16,6 & 226.412 & 8,9 & 21 & 12,5 & 288.579 & 11 & 12 & 14,1 & 190.476 & 5,4 \\
\hline $20.000-30.000$ & 14 & 11,1 & 222.437 & 12,4 & 3 & 3,2 & 9.309 & 3,7 & 8 & 8,3 & 183.802 & 7,2 & 14 & 8,3 & 345.537 & 13 & 9 & 10,5 & 218.869 & 6,2 \\
\hline $30.000-40.000$ & 4 & 3,1 & 144.643 & 8,1 & 5 & 5,3 & 169.760 & 9,1 & 10 & 10,4 & 334.019 & 13 & 10 & 5,9 & 354.197 & 13 & 4 & 4,7 & 142.919 & 4 \\
\hline $40.000-50.000$ & 2 & 1,5 & 88.488 & 4,9 & 4 & 4,3 & 183.654 & 9,9 & 5 & 5,2 & 227.187 & 8,9 & 12 & 7,1 & 543.618 & 20 & 5 & 5,8 & 228.920 & 6,5 \\
\hline $50.000-60.000$ & 7 & 5,5 & 394.412 & 22,1 & 3 & 3,2 & 162.647 & 8,8 & 5 & 5,2 & 267.186 & 11 & 3 & 1,7 & 156.884 & 5,7 & 6 & 7 & 335.180 & 9,6 \\
\hline $60.000-70.000$ & 1 & 0,7 & 69.030 & 3,8 & 2 & 2,1 & 134.807 & 7,2 & 0 & 0 & 7 & 0 & 4 & 2,3 & 265.804 & 9,7 & 3 & 3,5 & 193.079 & 5,5 \\
\hline $70.000-80.000$ & 1 & 0,7 & 74.240 & 4,1 & 1 & 1 & 70.175 & 3,7 & 4 & 4,1 & 292.799 & 12 & 2 & 1,1 & 150.120 & 5,5 & 2 & 2,3 & 147.228 & 4,2 \\
\hline $80.000-90.000$ & 0 & 0 & 0 & 0 & 1 & 1 & 85.179 & 4,6 & 0 & 0 & 0 & 0 & 1 & 0,5 & 81.345 & 2,9 & 2 & 2,3 & 173.610 & 4,9 \\
\hline $90.000-10.0000$ & 1 & 0,7 & 95.682 & 5,3 & 2 & 2,1 & 187.959 & 10,1 & 1 & 1 & 98.000 & 3,8 & 2 & 1,1 & 187.409 & 6,9 & 3 & 3,5 & 285.144 & 8,1 \\
\hline $\begin{array}{l}\text { Más de } 100.000 \\
\text { mrs. }\end{array}$ & 2 & 1,5 & 243.583 & 13,6 & 3 & 3,2 & 434.019 & 23,5 & 5 & 5,2 & 753.757 & 30 & 0 & 0 & 0 & 0 & 9 & 10,5 & 1.437 .375 & 41,1 \\
\hline Total & 126 & 100 & 1.783 .753 & 100 & 93 & 100 & $1,846.782$ & 100 & 96 & 100 & 2.536 .481 & 100 & 167 & 100 & 2.716 .012 & 100 & 85 & 100 & 3.490 .506 & 100 \\
\hline
\end{tabular}

Fuente: Archivo General de Simancas Cámara de Castilla, Diversos, leg.4, doc. $n^{\circ} 30$ y doc. $n^{\circ} 31$; Leg. 3, doc. no 24; Escribanía Mayor de Rentas, leg. $n^{\circ}$ 90/1 y Archivo de la Real Chancillería de Valladolid. Pleitos Civiles. Pérez Alonso (fenecidos). Cajas 102-5, 103-1 y 104-1.

Mer $=$ mercaderes; mrs $=$ maravedís. 


\begin{tabular}{|c|c|c|c|c|c|c|}
\hline NOMBRE DEL MERCADER & ORIGEN / PROFESIÓN & AÑO 1495 & AÑO 1496 & AÑO 1497 & AÑO 1502 & AÑO 1510 \\
\hline Bernaldo Pinelo & genovés & 127377 & 51372 & 75133 & --- & --- \\
\hline Antonio Pinelo & genovés & --- & 4044 & 5533 & 11318 & --- \\
\hline Juan Bautista Pinelo & genovés & --- & --- & --- & --- & 5768 \\
\hline Bernaldino de Isla & burgalés & 8553 & 12577 & 71496 & 50000 & --- \\
\hline Pero Venegas & trapero & 14505 & 13000 & 7263 & 6240 & --- \\
\hline Cosme y Francisco de Riberol & genoveses & 116206 & --- & --- & --- & --- \\
\hline Francisco Riberol & genovés & --- & 133000 & 203653 & 52971 & 19228 \\
\hline Bartolomé Riberol & genovés & --- & --- & --- & --- & 73228 \\
\hline Bernaldo Grimaldo & genovés & 74240 & 195064 & 117293 & 61277 & --- \\
\hline Jácomo Grimaldo & genovés & --- & --- & --- & --- & 156214 \\
\hline Nicolás Grimaldo & genovés & --- & --- & --- & --- & 74000 \\
\hline Jácome de Çervanis & genovés & 10998 & 49757 & 121736 & --- & --- \\
\hline Antonio de Çervanis & genovés (?) & --- & --- & --- & 29227 & 36839 \\
\hline Angel de Negrón & genovés & 55781 & 37676 & 30000 & --- & --- \\
\hline Diego de Alcocer & jurado & 39520 & 68000 & 59000 & 35203 & 21459 \\
\hline Doménigo (?) Calvo & genovés & --- & 2619 & 2000 & 79755 & --- \\
\hline Julián Calvo & genovés & --- & --- & --- & 13833 & --- \\
\hline Octavio Calvo & genovés & --- & --- & --- & --- & 22000 \\
\hline Rodrigo de Ballesteros & burgalés & 95682 & 85179 & 163117 & 91394 & --- \\
\hline Juan de Ballesteros & burgalés & --- & --- & --- & --- & 321733 \\
\hline
\end{tabular}




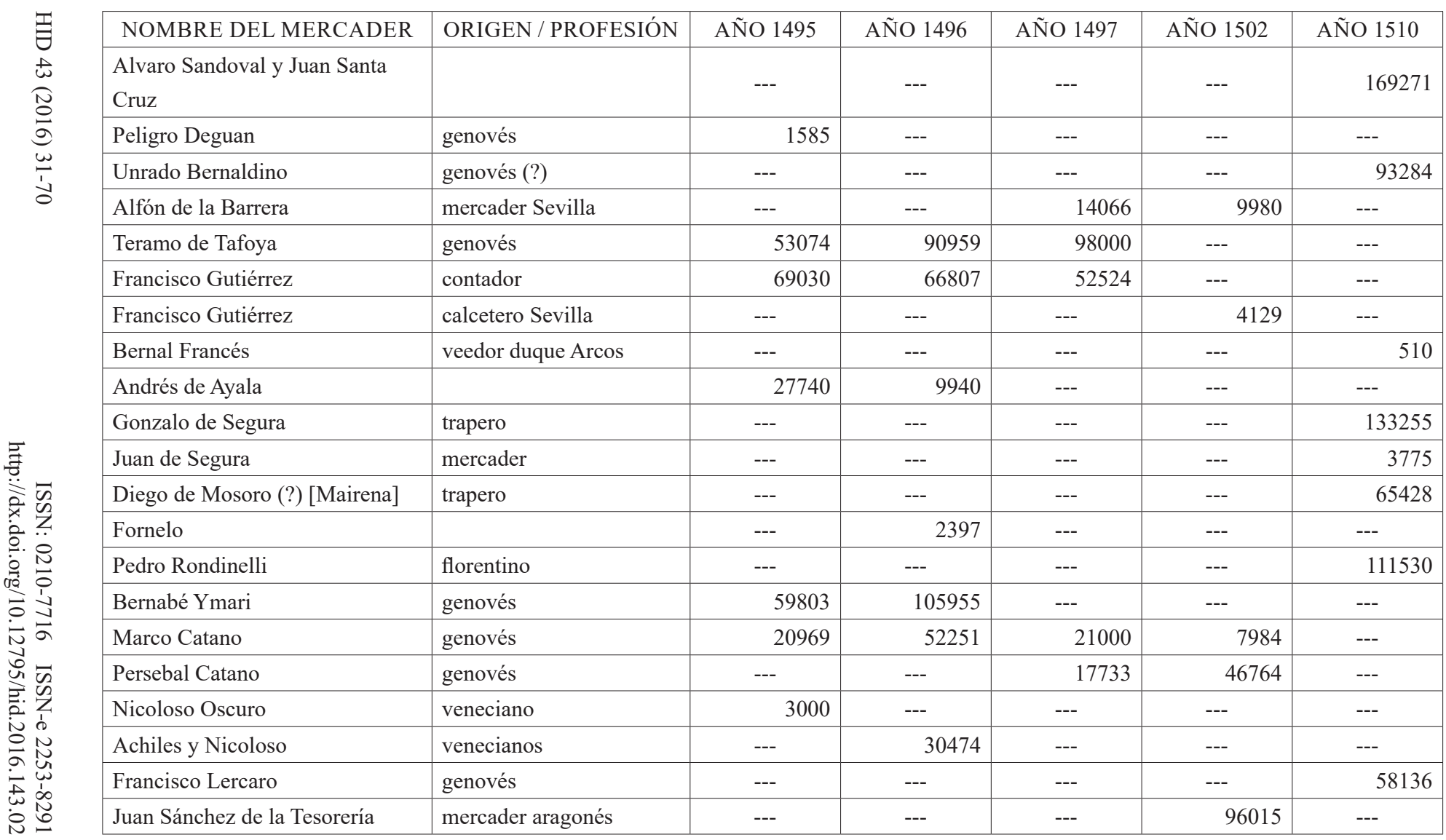




\begin{tabular}{|c|c|c|c|c|c|c|c|}
\hline$\vec{E}$ & NOMBRE DEL MERCADER & ORIGEN / PROFESIÓN & AÑO 1495 & AÑO 1496 & AÑO 1497 & AÑO 1502 & AÑO 1510 \\
\hline$\ddot{\bar{a}} \div$ & Pero Viçençio Doria & genovés & 9551 & 43620 & --- & --- & --- \\
\hline 응 & Pero Viçencio y Sebastián Doria & genoveses & -- & --- & 147958 & --- & -- \\
\hline : & Francisco Doria & mercader genovés & --- & --- & 9428 & 46831 & --- \\
\hline${ }_{0}^{\circ}$ & Gregorio Doria & genovés & --- & --- & --- & 66710 & -- \\
\hline $\bar{N} \bar{N}$ & Marco Castellón & genovés & --- & --- & 12225 & --- & -- \\
\hline 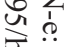 & Luco Batista Adorno & genovés & --- & --- & --- & 34987 & 15000 \\
\hline : N & Julián Adorno & genovés & -- & -- & --- & 5454 & --- \\
\hline 崩 & Juan de Oliva & & --- & --- & --- & --- & 1600 \\
\hline 它 & Alfonso Bolante & & --- & --- & --- & --- & 11975 \\
\hline i & Benito de Pomar & & --- & --- & --- & --- & 22161 \\
\hline & Andrés Pesquera y Miguel Silva & burgaleses & --- & --- & --- & --- & 5292 \\
\hline & Juan del Molino & & --- & --- & --- & --- & 17800 \\
\hline & Diego Benito & & --- & --- & --- & --- & 15523 \\
\hline & Diego López & mercader Sevilla & --- & --- & --- & -- & 4508 \\
\hline & Diego López y Juan Ruiz & & --- & --- & --- & --- & 5000 \\
\hline & Alfón Llerena & & --- & --- & 3348 & --- & --- \\
\hline$I$ & Juan de Nájera & burgalés & 26106 & 440 & 5000 & --- & --- \\
\hline$=$ & Andrés de Tovar & burgalés & --- & --- & 16676 & 2040 & --- \\
\hline$\stackrel{\vec{\omega}}{\mathrm{N}}$ & Pedro Fernández de Toledo & cambiador Sevilla & -- & --- & --- & 38600 & --- \\
\hline$\frac{0}{2}$ & Pedro de Dueñas & burgalés & 27535 & 19029 & 32488 & --- & -- \\
\hline$\underbrace{\omega}$ & Miguel y Juan de la Font & mercaderes catalanes & --- & --- & --- & --- & 59754 \\
\hline
\end{tabular}




\begin{tabular}{|c|c|c|c|c|c|c|}
\hline NOMBRE DEL MERCADER & ORIGEN / PROFESIÓN & AÑO 1495 & AÑO 1496 & AÑO 1497 & AÑO 1502 & AÑO 1510 \\
\hline Juan Millet & inglés & --- & 1967 & 51000 & --- & --- \\
\hline Juan Tomás Espínola & & --- & --- & --- & --- & 36318 \\
\hline Rodrigo de Carrión & burgalés & 58951 & 70175 & 10616 & 44000 & --- \\
\hline Andrés de Carrión & burgalés & --- & --- & --- & 25125 & --- \\
\hline $\begin{array}{l}\text { Martin de Arraçola y Juan de } \\
\text { Milla (?) }\end{array}$ & & 57295 & --- & --- & --- & --- \\
\hline $\begin{array}{l}\text { Alfonso de Alveda y Gómez } \\
\text { Morales }\end{array}$ & & --- & --- & --- & --- & 59554 \\
\hline Diego Blandón & & --- & 500 & --- & --- & --- \\
\hline Francisco Pinelo & genovés & 5915 & 2600 & --- & --- & --- \\
\hline Alfonso Dávila & & --- & --- & --- & --- & 5000 \\
\hline Francisco del Alcázar & jurado Sevilla & --- & -- & --- & 1775 & $(?)$ \\
\hline Francisco de Burgos & & 7100 & 1800 & --- & --- & --- \\
\hline Juan Lomelín & genovés & 3230 & 40902 & 8000 & --- & --- \\
\hline Diego de Montoro (?) & & --- & --- & --- & --- & 15000 \\
\hline Juan de Santiago & & 1006 & --- & --- & --- & --- \\
\hline Polo de (?) y Lázaro de Arba & & --- & --- & --- & --- & 26710 \\
\hline Doña Elvira de Narváez & & --- & --- & 5000 & --- & --- \\
\hline Diego de Mendoza & comendador & --- & -- & --- & --- & 800 \\
\hline Galeoto de Çerra & & 16807 & --- & --- & --- & --- \\
\hline Pero Miguel & valenciano & 400 & 780 & 200 & 35242 & --- \\
\hline Alfón Rodríguez & trapero & 37223 & 38180 & 17610 & 49670 & --- \\
\hline
\end{tabular}




\begin{tabular}{|c|c|c|c|c|c|c|}
\hline NOMBRE DEL MERCADER & ORIGEN / PROFESIÓN & AÑO 1495 & AÑO 1496 & AÑO 1497 & AÑO 1502 & AÑO 1510 \\
\hline Nicolás de Durango & vizcaíno & 3245 & --- & 1652 & --- & --- \\
\hline Juan Guars & inglés & 41128 & --- & --- & --- & 7770 \\
\hline Juan Ibáñez & & --- & --- & --- & --- & 41999 \\
\hline Gonzalo Fernández & mercader & 54316 & --- & --- & 44806 & (?) \\
\hline Alvaro de Osorio & & --- & 7200 & 4350 & --- & --- \\
\hline Jácome Pinelo & genovés & --- & 3956 & --- & --- & --- \\
\hline Franco Leardo & genovés & --- & --- & --- & --- & 14106 \\
\hline Doña Catalina de Ribera & & 3659 & 3600 & 10000 & 490 & --- \\
\hline Duquesa de Medina Sidonia & & 2226 & 400 & --- & --- & --- \\
\hline $\begin{array}{l}\text { La señora marquesa de } \\
\text { Montemayor }\end{array}$ & & --- & --- & --- & 400 & --- \\
\hline Jácome de Riberol & genovés & 25190 & 22738 & 32702 & 2640 & --- \\
\hline Alonso de M. & burgalés & 19369 & --- & --- & --- & --- \\
\hline Juan de Torren & & --- & --- & --- & --- & 5000 \\
\hline Alonso de Villada & jurado & 6495 & --- & 14200 & --- & --- \\
\hline Alvaro de Valladolid & burgalés & 55192 & 300 & 71000 & 81345 & --- \\
\hline Pero de Valladolid & jurado & --- & --- & 23796 & 12639 & --- \\
\hline Juan de Valladolid & burgalés & --- & --- & --- & 10740 & --- \\
\hline
\end{tabular}




\begin{tabular}{|c|c|c|c|c|c|c|}
\hline NOMBRE DEL MERCADER & ORIGEN / PROFESIÓN & AÑO 1495 & AÑO 1496 & AÑO 1497 & AÑO 1502 & AÑO 1510 \\
\hline Francisco de Açova (?) & & --- & --- & --- & --- & 88610 \\
\hline Alfón de Mazuelo & burgalés & --- & 3430 & --- & --- & --- \\
\hline Andrés de Córdoba & & --- & --- & --- & --- & 5000 \\
\hline Batista Melo & & 2168 & --- & --- & --- & --- \\
\hline Luis de Riberol & genovés & 7464 & 6741 & 2561 & 3920 & --- \\
\hline Valian Salvago & genovés & 6975 & 12871 & 22360 & --- & --- \\
\hline Andrés Paredes & burgalés & --- & --- & --- & 35469 & --- \\
\hline Antono Liron & & 2324 & --- & --- & --- & --- \\
\hline Diego Pérez y Juan de Molina & & --- & --- & --- & --- & 5000 \\
\hline Antonio Boticario & & --- & --- & 14200 & 4798 & --- \\
\hline Diego Darmas & & --- & --- & --- & --- & 7381 \\
\hline Alonso de Lugo & Mercader de Sanlúcar & --- & 2500 & --- & --- & --- \\
\hline Pero Velásquez & & --- & --- & --- & 639 & --- \\
\hline Tomás Mallar y Roberto (?) & ingleses & --- & --- & --- & --- & 110614 \\
\hline Gonzalo de Jerez & & 300 & --- & --- & --- & --- \\
\hline Fernando de Coruña & burgalés & --- & --- & --- & 2825 & --- \\
\hline Francisco de Esquivel & & --- & --- & --- & 1920 & --- \\
\hline Alfón de Jerez & & --- & 4729 & --- & --- & --- \\
\hline Diego de Sevilla & mercader Sevilla & 35900 & 49375 & 56054 & 32857 & 157904 \\
\hline Diego de Sevilla, el mozo & & --- & --- & --- & --- & 10522 \\
\hline Juan Ortiz & candelero & 9222 & --- & --- & 31384 & --- \\
\hline
\end{tabular}




\begin{tabular}{|c|c|c|c|c|c|c|c|}
\hline$\vec{E}$ & NOMBRE DEL MERCADER & ORIGEN / PROFESIÓN & AÑO 1495 & AÑO 1496 & AÑO 1497 & AÑO 1502 & AÑO 1510 \\
\hline & Juan Ortiz, el negro & & --- & --- & --- & 2392 & --- \\
\hline$\approx 0$ & Alonso de Godoy & candelero & 8245 & --- & --- & 17659 & --- \\
\hline & Francisco Fernández Lorca & mercader Sevilla & -- & -- & --- & 220 & -- \\
\hline & Francisco Fernández & candelero & --- & --- & --- & 450 & --- \\
\hline & Pero Fernández & candelero & --- & --- & --- & 1372 & --- \\
\hline & Pero Fernández Cabrón & candelero & --- & --- & -- & 3202 & -- \\
\hline 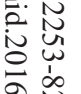 & $\begin{array}{l}\text { Pero Fernández, sobrino del } \\
\text { contador }\end{array}$ & & --- & --- & --- & 4460 & --- \\
\hline & Martín Centurión & genovés & --- & --- & --- & 38670 & --- \\
\hline 우 & (?) Centurión & genovés & --- & --- & --- & --- & 7655 \\
\hline & Alfón de Sevilla & & --- & 1438 & --- & --- & --- \\
\hline & Pero Ortiz, el viejo & & 7184 & --- & --- & --- & --- \\
\hline & Luis Ortiz, su hijo & & 4394 & -- & -- & 5851 & -- \\
\hline & Pero Ortiz de la Pez & & --- & --- & --- & 5335 & --- \\
\hline & Rodrigo Ortiz & jurado Sevilla & --- & --- & --- & 1410 & --- \\
\hline & Esteban Fernández & portugués & --- & --- & 5183 & --- & --- \\
\hline & Esteban Buen Vecino & & --- & --- & -- & 7900 & -- \\
\hline$\exists$ & Escalante & cambiador & --- & 2920 & -- & --- & -- \\
\hline 屯 & Bartolomé Ortiz & & 5015 & -- & -- & 3924 & -- \\
\hline 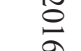 & Luis de Herrera & trapero & --- & --- & -- & --- & 39244 \\
\hline 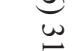 & Cristóbal Rodríguez & candelero & 7160 & --- & --- & 11163 & --- \\
\hline '̇ & Antonio Mirón & valenciano (?) & --- & --- & --- & 9500 & --- \\
\hline
\end{tabular}




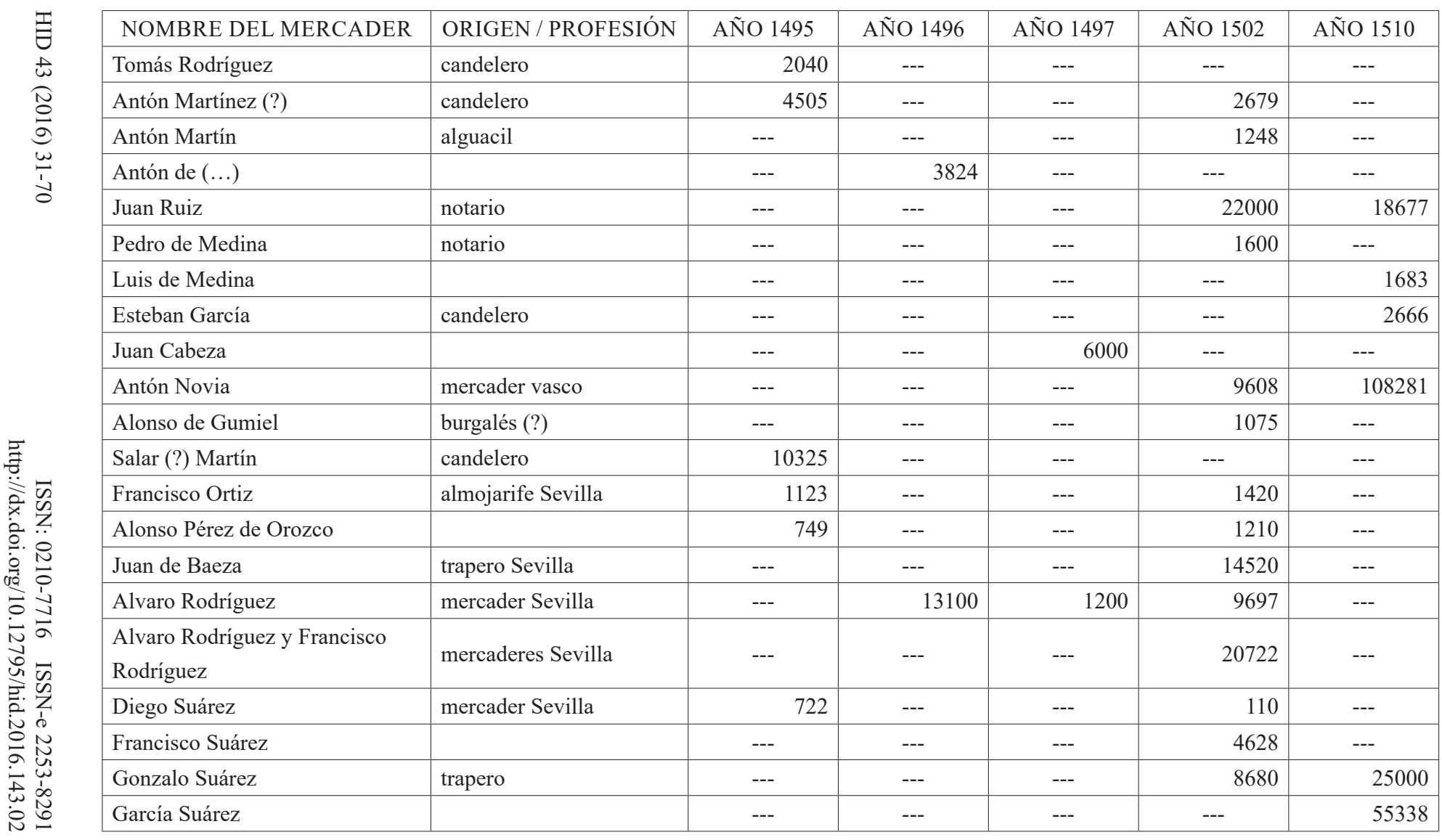




\begin{tabular}{|c|c|c|c|c|c|c|}
\hline NOMBRE DEL MERCADER & ORIGEN / PROFESIÓN & AÑO 1495 & AÑO 1496 & AÑO 1497 & AÑO 1502 & AÑO 1510 \\
\hline Juan Mallea & vizcaíno & --- & --- & --- & 41850 & --- \\
\hline Isabel Martínez, viuda & & 3655 & --- & --- & 1189 & --- \\
\hline Pedro de Reynaga & & --- & --- & --- & 13410 & --- \\
\hline Pedro de Eris (?) & mercader & --- & --- & --- & --- & 45825 \\
\hline Alonso González & mayordomo iglesia & --- & --- & --- & 1000 & --- \\
\hline Gonzalo de Saavedra & mariscal & --- & --- & 1000 & --- & --- \\
\hline Alvar Gutiérrez & mercader Sevilla & --- & --- & --- & 10622 & --- \\
\hline Andrés Rodríguez & & 2040 & --- & --- & --- & --- \\
\hline Pero Vázquez & & 1016 & --- & --- & --- & 3120 \\
\hline Lope Fernández & mercader vizcaíno & --- & --- & --- & --- & 46000 \\
\hline $\begin{array}{l}\text { Pero Gutiérrez y Alonso de } \\
\text { Salamanca }\end{array}$ & & --- & 2200 & --- & --- & --- \\
\hline Juan de Çea & Sevilla & --- & --- & --- & 868 & --- \\
\hline Fernad García & & 85 & --- & --- & --- & --- \\
\hline Alonso de Salinas & burgalés & --- & --- & --- & 825 & 45846 \\
\hline Pero García & & --- & --- & --- & 13272 & --- \\
\hline
\end{tabular}




\begin{tabular}{|c|c|c|c|c|c|c|}
\hline NOMBRE DEL MERCADER & ORIGEN / PROFESIÓN & AÑO 1495 & AÑO 1496 & AÑO 1497 & AÑO 1502 & AÑO 1510 \\
\hline $\begin{array}{l}\text { Bartolomé Rodríguez y García de } \\
\text { Çervanes }\end{array}$ & & --- & 4000 & --- & --- & --- \\
\hline Francisco de Lora & & 160 & --- & --- & --- & --- \\
\hline La mujer de Alonso de Masco & & 866 & --- & --- & --- & --- \\
\hline Bartolomé de Carmona & trapero & --- & --- & 3449 & 2930 & --- \\
\hline Alonso Martín de Carmona & & --- & --- & --- & 110 & --- \\
\hline Alonso Martín & gallego & --- & --- & --- & 220 & --- \\
\hline Antón de Segura & trapero & --- & --- & 40000 & 70365 & --- \\
\hline Pero de Jerez & & --- & 3076 & --- & --- & --- \\
\hline Pedro de Jerez y Juan de Jerez & mercaderes Sevilla & --- & --- & --- & 27068 & --- \\
\hline Francisco de Jerez & & 214 & --- & --- & --- & --- \\
\hline Berenguel de Ralfos & catalán (?) & --- & 2356 & 19661 & --- & --- \\
\hline Diego Martínez & candelero & --- & --- & --- & 2104 & --- \\
\hline Luis García de Palma & & 1525 & --- & --- & --- & --- \\
\hline Juan de Palma & burgalés & --- & --- & 11375 & 9640 & --- \\
\hline Pedro de Palma & & --- & --- & --- & --- & 100000 \\
\hline Alonso Fernández & jurado Sevilla & --- & --- & --- & 1060 & --- \\
\hline Juan Rodríguez & & --- & --- & 4000 & --- & --- \\
\hline Ochoa López & mercader vasco & --- & --- & --- & 46360 & 13284 \\
\hline Juan Rodríguez de Padilla & & 321 & --- & --- & & --- \\
\hline Pedro de Padilla & & --- & --- & --- & 1375 & --- \\
\hline Juan de Toro & & --- & 5922 & --- & --- & --- \\
\hline
\end{tabular}




\begin{tabular}{|c|c|c|c|c|c|c|}
\hline NOMBRE DEL MERCADER & ORIGEN / PROFESIÓN & AÑO 1495 & AÑO 1496 & AÑO 1497 & AÑO 1502 & AÑO 1510 \\
\hline Pero de Castro & espejero & --- & 3718 & --- & --- & --- \\
\hline Diego de Castro & burgalés & --- & --- & --- & 31791 & 29087 \\
\hline Juan Fernández de Castro & burgalés & --- & --- & --- & --- & 17290 \\
\hline Juan de Rojas & & 12410 & --- & --- & --- & --- \\
\hline Luis Alonso Condesal & & 0 & --- & 2950 & & --- \\
\hline Cristóbal Córdoba & & 6460 & --- & --- & --- & --- \\
\hline Rodrigo de Córdoba & almojarife Sevilla & --- & --- & --- & 1130 & --- \\
\hline Juan de Córdoba & & --- & 1050 & & --- & --- \\
\hline Manuel de Córdoba & trapero & --- & --- & --- & --- & 10760 \\
\hline Lope de Briones & & --- & --- & --- & 6012 & --- \\
\hline Martín de Perondo & & --- & --- & --- & --- & 60850 \\
\hline Juan Alemán & trapero & --- & --- & 1860 & --- & --- \\
\hline Ruy Sánchez de Ojeda & & 4505 & --- & --- & --- & --- \\
\hline Francisco de Ojeda & candelero & --- & --- & --- & 6542 & --- \\
\hline Andrés de Jerez & & --- & 2190 & --- & --- & --- \\
\hline Diego Álvarez & Sevilla & --- & --- & --- & 5730 & --- \\
\hline
\end{tabular}




\begin{tabular}{|c|c|c|c|c|c|c|}
\hline NOMBRE DEL MERCADER & ORIGEN / PROFESIÓN & AÑO 1495 & AÑO 1496 & AÑO 1497 & AÑO 1502 & AÑO 1510 \\
\hline Pero Díaz & & 2046 & --- & --- & --- & --- \\
\hline Alonso de Medina & burgalés-jurado & --- & 250 & 52800 & 29042 & 6344 \\
\hline Rodrigo de Medina & almojarife Sevilla & --- & --- & --- & 680 & --- \\
\hline Miguel Jiménez & & 160 & --- & --- & --- & --- \\
\hline Fernando de Oviedo & & --- & --- & 500 & --- & --- \\
\hline Fernando de Sevilla & & --- & --- & --- & 0 & 5000 \\
\hline Juan Jiménez de Spina & & --- & --- & --- & 0 & 19126 \\
\hline Juan Díaz & & --- & --- & 3580 & --- & --- \\
\hline Juan Díaz y Juan de Triana & & --- & --- & 1000 & & --- \\
\hline Alonso de Sevilla & mercader Sevilla & --- & --- & --- & 8600 & --- \\
\hline Juan Batista Malvazín & & --- & --- & --- & 13935 & --- \\
\hline Juan Batista & & --- & -- & --- & --- & 91860 \\
\hline Juan de Marchena & & 37 & --- & --- & --- & --- \\
\hline Diego de Mairena & & 1657 & --- & --- & 4072 & --- \\
\hline Juan de Burgos & burgalés & --- & --- & --- & 42326 & 168573 \\
\hline Fernando de Burgos & & --- & --- & --- & 17508 & --- \\
\hline Fernando Barço & & --- & --- & --- & --- & 22552 \\
\hline Inés Peraza & Señora de Canarias & --- & 2676 & --- & --- & --- \\
\hline Pero Rodríguez Peligro & & 595 & & --- & --- & --- \\
\hline Beniraba (?) & & --- & --- & --- & 0 & 50362 \\
\hline Ruy (?) & candelero & --- & --- & --- & 0 & 13965 \\
\hline
\end{tabular}




\begin{tabular}{|c|c|c|c|c|c|c|}
\hline NOMBRE DEL MERCADER & ORIGEN / PROFESIÓN & AÑO 1495 & AÑO 1496 & AÑO 1497 & AÑO 1502 & AÑO 1510 \\
\hline Alonso de toledo & & --- & --- & --- & 12876 & --- \\
\hline Antono Ybona (?) & & 1570 & --- & --- & --- & --- \\
\hline Juan Pérez de Larrazabal & & --- & 13328 & --- & --- & --- \\
\hline Juan Guarque & inglés & 7117 & --- & 44646 & --- & --- \\
\hline $\begin{array}{l}\text { Guillén Grande, Juan Guarque y } \\
\text { Francisco Morano }\end{array}$ & & 3800 & 97000 & --- & --- & --- \\
\hline $\begin{array}{l}\text { Juan Guarque y Francisco } \\
\text { Moreno }\end{array}$ & & --- & 10800 & --- & --- & --- \\
\hline $\begin{array}{l}\text { Juan Guarque y Francisco } \\
\text { Moreno }\end{array}$ & & --- & 5270 & --- & --- & --- \\
\hline Francisco Moreno & trapero & --- & 16790 & --- & 7745 & --- \\
\hline Diego Bueno & trapero & --- & --- & --- & 5600 & --- \\
\hline Cristóbal de Aguilera & & --- & --- & --- & 7414 & --- \\
\hline La mujer de Diego Fernández & & --- & --- & --- & 3523 & --- \\
\hline Guillén Fasa (?) & & 22000 & --- & --- & --- & --- \\
\hline Guillermo Amor (?) & & 15500 & --- & --- & --- & --- \\
\hline Diego Ramos & & --- & --- & --- & 1398 & --- \\
\hline Pedro Lerca & & 11000 & 4890 & 2500 & --- & --- \\
\hline
\end{tabular}




\begin{tabular}{|c|c|c|c|c|c|c|}
\hline NOMBRE DEL MERCADER & ORIGEN / PROFESIÓN & AÑO 1495 & AÑO 1496 & AÑO 1497 & AÑO 1502 & AÑO 1510 \\
\hline Pedro de Aranda & burgalés & --- & --- & 18603 & 6500 & --- \\
\hline Antonio Doro & & --- & --- & --- & 8857 & --- \\
\hline Bartolomé de Lalo & & 47360 & 20271 & 49787 & --- & --- \\
\hline Diego Ortiz, el mozo & & 2318 & --- & --- & 2310 & --- \\
\hline Donato Nicolino & & 15610 & 33319 & 32914 & --- & --- \\
\hline Antón García & candelero & 1757 & --- & --- & --- & --- \\
\hline Pero Chacón & trapero Sevilla & --- & --- & --- & 2580 & --- \\
\hline Antón de Rojas & buhonero & 990 & --- & --- & 980 & --- \\
\hline Safra ? Sánchez & & 1062 & --- & --- & --- & --- \\
\hline García Fernández & mercader & --- & 59024 & 33400 & & --- \\
\hline Alonso de Montalbán & & --- & --- & --- & 11978 & --- \\
\hline Gutiérrez de Prado & almojarife Sevilla & 400 & --- & --- & 6779 & --- \\
\hline Alonso de Prado & mercader Sevilla & --- & --- & --- & 16878 & --- \\
\hline Francisco Núñez de (...) & & & --- & 600 & & --- \\
\hline Juan Núñez & candelero & 935 & --- & --- & & --- \\
\hline Alfonso de Herrera & almojarife Sevilla & --- & --- & --- & 1000 & --- \\
\hline Alonso Pérez Melgarejo & & 213 & --- & --- & & --- \\
\hline Pero Batista & & --- & 968 & --- & & -- \\
\hline Blas Méndez & candelero & --- & --- & --- & 1555 & --- \\
\hline Juan Quijada & & --- & --- & --- & 1265 & --- \\
\hline Don Pedro de León & escribano Audiencia & --- & --- & --- & 495 & -- \\
\hline
\end{tabular}




\begin{tabular}{|c|c|c|c|c|c|c|}
\hline NOMBRE DEL MERCADER & ORIGEN / PROFESIÓN & AÑO 1495 & AÑO 1496 & AÑO 1497 & AÑO 1502 & AÑO 1510 \\
\hline Fernando de Valencia & & --- & --- & 1235 & & --- \\
\hline Fernando de Béjar & trapero & --- & --- & --- & 0 & 57036 \\
\hline Bartolomé García & carpintero & 213 & --- & --- & 1485 & --- \\
\hline Juan Sánchez (el Albo ?) & trapero Sevilla (?) & --- & --- & --- & 15459 & --- \\
\hline Hernán Pérez & mercader & --- & 4888 & --- & --- & --- \\
\hline Juan de Anguina (Angara) & & 11930 & --- & 9399 & 7226 & --- \\
\hline Pero Martínez de Zabala & & 26694 & 8120 & 36217 & & --- \\
\hline Juan Martínez de Lyly & mercader vasco & --- & --- & --- & 22380 & --- \\
\hline Tomás Ciejas (?) & & --- & --- & --- & 0 & 49250 \\
\hline Juan de Ledesma & & --- & 1500 & --- & & --- \\
\hline Juan López de Recalde & mercader vasco & 8000 & 3630 & 59814 & 43913 & 3375 \\
\hline Martín de Recalde & mercader vasco & --- & --- & --- & 10800 & --- \\
\hline Pero de Vergara & & --- & 6795 & 17364 & --- & 9695 \\
\hline Miguel de Vergara & mercader vasco & 25000 & 7898 & 23890 & 15858 & --- \\
\hline Martín Pérez de Vergara & & --- & --- & 1123 & --- & --- \\
\hline Martín Pérez & & --- & --- & --- & --- & 6662 \\
\hline
\end{tabular}




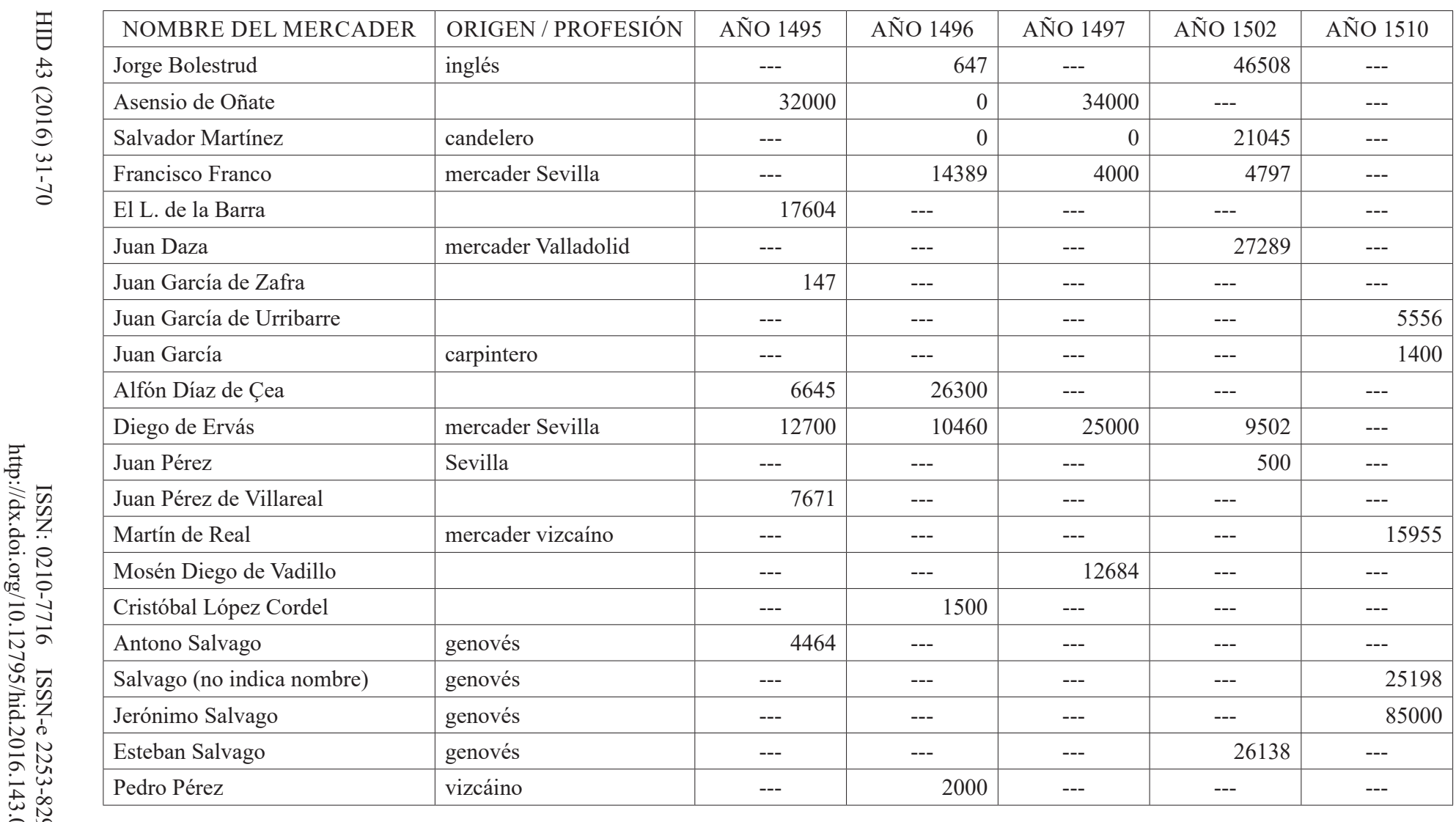




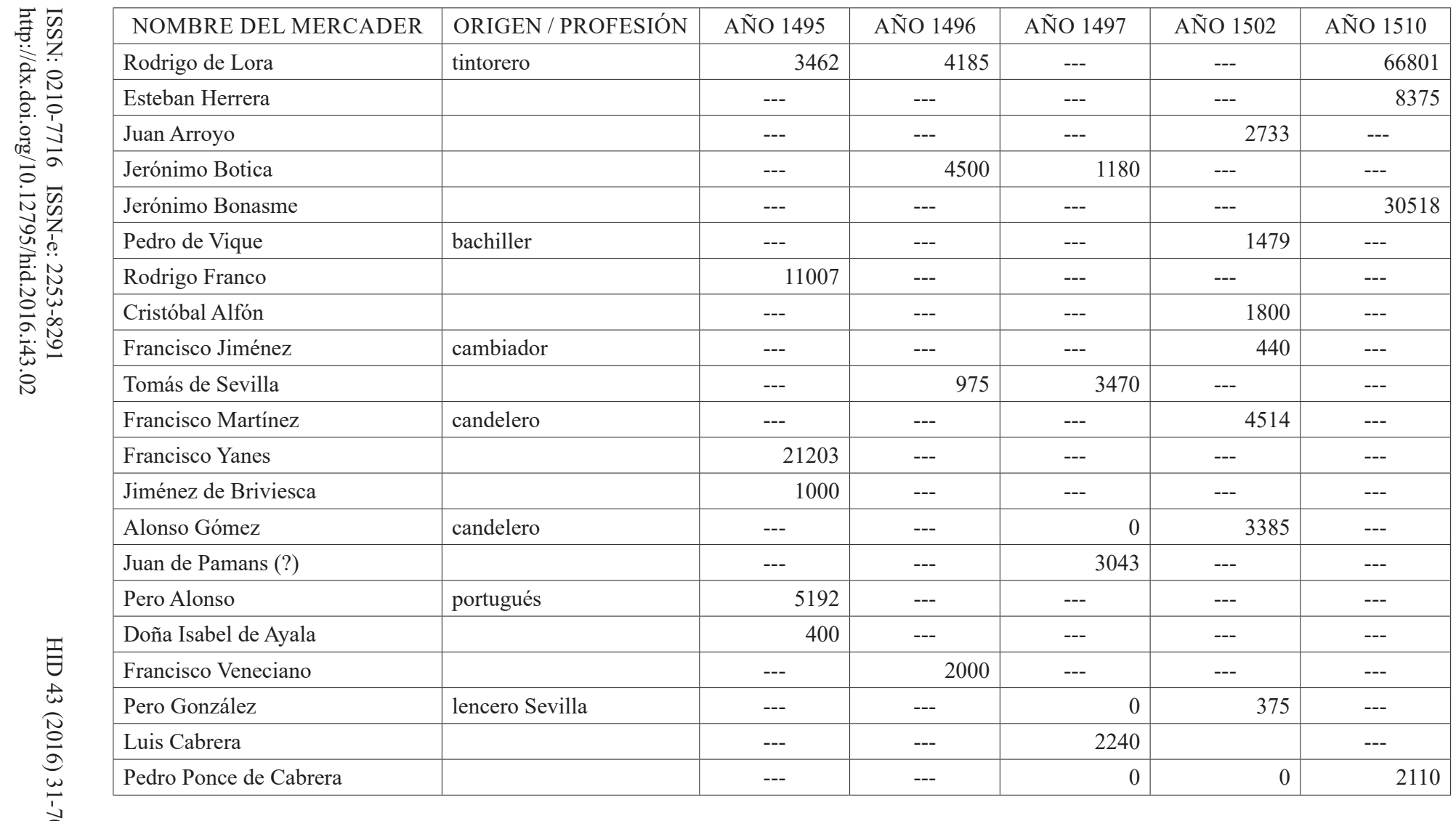




\begin{tabular}{|c|c|c|c|c|c|c|}
\hline NOMBRE DEL MERCADER & ORIGEN / PROFESIÓN & AÑO 1495 & AÑO 1496 & AÑO 1497 & AÑO 1502 & AÑO 1510 \\
\hline Manuel Çisbón & mercader Sevilla & 3848 & 3884 & 32114 & 68091 & 9554 \\
\hline Bernal (?) De Ralfas (?) & & 1318 & --- & --- & --- & --- \\
\hline Alonso de Maçalo (?) & & 1284 & --- & --- & --- & --- \\
\hline Juan de Gibraleón & trapero Sevilla & --- & --- & 6000 & 12100 & --- \\
\hline Juan de Loya & lencero & --- & 6760 & 22096 & & --- \\
\hline Manuel de Loya & lencero Sevilla & --- & --- & 0 & 20262 & --- \\
\hline Gonzalo Pérez Jarada & arrendador rentas & --- & --- & 0 & 4956 & --- \\
\hline Juan Rodríguez Astero & & 1116 & 2574 & 3600 & --- & --- \\
\hline Hernándo de (...) & & --- & 750 & --- & --- & --- \\
\hline Marcos de Luzio & & --- & --- & --- & 1600 & --- \\
\hline Francisco de M. & & 3405 & --- & --- & --- & --- \\
\hline Francisco de la Lonja & & 500 & --- & --- & --- & --- \\
\hline Alfonso de la Lonja & & --- & --- & --- & --- & 24702 \\
\hline Pedro de Torres & mercader Sevilla & --- & --- & --- & 12091 & --- \\
\hline Antonio de $(\ldots)$ & & 8865 & --- & --- & --- & --- \\
\hline Gregorio de Ayala & burgalés & --- & --- & --- & 53913 & --- \\
\hline Antonio de Nayron & genovés & --- & 8000 & 35384 & --- & 8147 \\
\hline Fernando de Yanguas & candelero & --- & --- & --- & 3477 & --- \\
\hline Luís Catano & genovés (?) & 10500 & --- & --- & --- & --- \\
\hline Pedro Descansa (?) & & --- & --- & 250 & --- & --- \\
\hline Pedro de Espinosa & & --- & --- & --- & --- & 7440 \\
\hline
\end{tabular}




\begin{tabular}{|c|c|c|c|c|c|c|}
\hline NOMBRE DEL MERCADER & ORIGEN / PROFESIÓN & AÑO 1495 & AÑO 1496 & AÑO 1497 & AÑO 1502 & AÑO 1510 \\
\hline Rodrigo de Sevilla & Sevilla & --- & --- & --- & 69726 & --- \\
\hline Juan de Cazaña & & --- & --- & 6600 & --- & --- \\
\hline Juan Brujas & inglés & --- & 30111 & 20660 & --- & --- \\
\hline Pedro Guajardo & & --- & --- & --- & 1409 & --- \\
\hline Alonso García & ballestero & --- & --- & --- & 330 & --- \\
\hline Martín de Plasencia & carnicero de Huévar & 1792 & 2715 & 44200 & 4619 & --- \\
\hline Juan Luçel & inglés & --- & 6120 & --- & --- & --- \\
\hline Martín de Arriazola & & --- & 17094 & 75170 & --- & --- \\
\hline Martín López de Aguinaga & & --- & --- & 5200 & --- & --- \\
\hline Asensio Vanes & & --- & --- & --- & 49588 & --- \\
\hline Juan López de Gallasti & mercader vasco & --- & --- & --- & 1200 & --- \\
\hline De iguala de los Asogas (?) & & --- & --- & 25000 & & --- \\
\hline Los esclavos de servicio & & --- & --- & --- & 2000 & --- \\
\hline El [lugarteniente] del Almirante & & --- & --- & --- & 6470 & --- \\
\hline
\end{tabular}

Fuente: AGS. Cámara de Castilla, Diversos, leg.4, doc. $n^{\circ} 30$ y doc. $n^{\circ}$ 31; Leg. 3, doc. $n^{\circ}$ 24; Expedientes de Hacienda, leg. 10; Escribanía Mayor de rentas, leg. no 90/1 y ARChV. Pleitos Civiles. Pérez Alonso (fenecidos). Cajas 102-5, 103-1 y 104-1.

Nota: Las cifras se expresan en maravedís. 


\section{BIBLIOGRAFÍA}

Alonso García, David (2004 a), Fisco, poder y monarquía en los albores de la modernidad: Castilla, 1504-1525, Universidad Complutense, Madrid, 2004.

Alonso García, David (2004 b), "Un mundo de financieros. La Hacienda Real de Castilla y sus arrendadores en las postrimerías del reinado", en Ribot, Luis, Valdeón, Julio y Maza, Elena, Isabel la Católica y su época, Valladolid, volumen I, pp. 499-518.

Alonso García, David (2007 c) El erario del reino. Fiscalidad en castilla a principios de la Edad Moderna, 1504-1525, Valladolid.

Aznar Vallejo, Eduardo (1982), La integración de las Islas Canarias en la Corona de Castilla, (1478-1526), La Laguna.

Aznar Vallejo, Eduardo y Palenzuela Domínguez, Natalia (2009), "El comercio andaluz en 1502. Las fuentes fiscales", en Val Valdivieso, María Isabel y Martínez Sopena, P. (dirs.), Castilla y el Mundo Feudal. Homenaje al profesor Julio Valdeón, vol. I, Valladolid, pp. 673-689.

Bello León, Juan Manuel (2005), "Contribución a la biografía del mercader genovés Francisco Riberol, 1458-1514”, en La Torre. Homenaje a Emilio Alfaro Hardisson, La Laguna, pp. 123-143.

Bello León, Juan Manuel (2006), "Notas para valorar la contribución de la expansión atlántica a la Hacienda Real castellana a finales de la Edad Media", Revista de Historia Canaria, 188, pp. 61-76.

Bello León, Juan Manuel (2007), La pesca en Andalucía y Canarias en el tránsito de la Edad Media a la Moderna (siglos XV-XVI), Santa Cruz de Tenerife.

Bello León, Juan Manuel (2012), “¿Quiénes eran los mercaderes de Sevilla a finales de la Edad Media?”, en Solórzano Telechea, Jesús, Bochaca, Michel y Aguiar Andrade, Amelia, Gentes del mar en la ciudad atlántica medieval, Logroño, pp. 249-274.

Carande, Ramón. y Carriazo, Juan de Mata (1968), El Tumbo de los Reyes Católicos del concejo de Sevilla, Sevilla.

Carvajal de la Vega, David (2010) "El control del negocio fiscal: las Hojas e Informaciones de bienes de arrendatarios y fiadores en la Hacienda castellana bajomedieval", en Collantes de Terán Sánchez, Antonio y Bonachía Hernando, Juan Antonio (coord.), Fuentes para el estudio del negocio fiscal y financiero en los reinos hispánicos (siglos XIV-XVI), Madrid, pp. 171-204.

Carriazo Rubio, Juan Luís (2014), "Notas sobre la fiscalidad señorial: el almojarifazgo de Arcos de la Frontera a comienzos del siglo XV", en Borrero Fernández, Mercedes, Carrasco Pérez, Juan y Peinado Santaella, Rafael (edit.) Agentes de los sistemas fiscales en Andalucía y los reinos hispánicos (siglos XIII-XVII): un modelo comparativo, Madrid, pp. 193-210.

Casado Alonso, Hilario (2000), "Comercio, crédito y finanzas públicas en Castilla en la época de los Reyes Católicos”, en Bernal, A. (ed.), Dinero, moneda y crédito en la monarquía hispánica, Madrid, pp. 135-156. 
Castro Antolin, Mariano de (1978), "Consideraciones en torno al origen y concepto de almojarifazgo", en Actas del I Congreso de Historia de Andalucía. Andalucía Medieval I. Córdoba, pp. 435-442.

Collantes de Terán Sánchez, Antonio (1999), "Les impôts municipaux indirects, ordinariez et extraordinaires de Séville", en Menjoy, Denis y Sánchez Martínez, Manuel (coord.), La fiscalié des villes au Moyen Âge, 2. Les systèmes fiscaux, Toulouse, pp. 463-483.

García Fernández, Ernesto (coord.) 2012, Tesoreros, «arrendadores» y financieros en los reinos hispánicos: la Corona de Castilla y el Reino de Navarra (siglos $X I V-X V I I)$, Madrid.

González Arce, José Damián (1991), “El almojarifazgo de Sevilla. Una renta feudal", en VI Coloquio Internacional de Historia Medieval Andaluza. Las ciudades andaluzas (siglos XIII-XVI), Málaga, pp.151-159.

González Arce, José Damián (1993), "Documentos sobre el almojarifazgo de Sevilla", Historia. Instituciones. Documentos, 20, pp. 165-196.

González Arce, José Damián (1997), Las rentas del almojarifazgo de Sevilla”, Studia Histórica (Historia Medieval), 15, pp. 209-254.

González Arce, José Damián (2012 a), "De conjunto de rentas a impuesto aduanero. La transformación del almojarifazgo durante el siglo XIV en el reino de Murcia", Anuario de Estudios Medievales, 42/2, pp. 669-696.

González Arce, José Damián (2012 b), "Los beneficiarios de la fiscalidad medieval. El caso del diezmo del aceite del almojarifazgo de Sevilla en el siglo XV", Medievalismo, 22, pp. 99-137.

González Arce, José Damián, (2015), “La composición de los almojarifazgos señoriales del reino de Sevilla, siglos XIII-XV", Historia. Instituciones. Documentos, 41, pp. 243-273.

Ladero Quesada, Miguel Ángel (2008), Las Indias de Castilla en sus primeros años. Cuentas de la Casa de la Contratación (1503-1521), Madrid.

Ladero Quesada, Miguel Ángel (1969), "Almojarifazgo sevillano y comercio exterior de Andalucía en el siglo XV”, Anuario de Historia Económica y Social, $\mathrm{n}^{\mathrm{o}} 2$; pp. 69-116.

Ladero Quesada, Miguel Ángel (1973), La Hacienda Real de Castilla en el siglo $X V$, La Laguna.

Ladero Quesada, Miguel Ángel (1982 a), "Fiscalidad regia y sector terciario en la Andalucía Bajomedieval", en Actas del II Coloquio de Historia Medieval de Andalucía. Hacienda y comercio, Sevilla, pp. 7-38.

Ladero Quesada, Miguel Ángel (1982 b), El siglo XV en Castilla. Fuentes de renta y política fiscal, Barcelona.

Ladero Quesada, Miguel Ángel (1999), Legislación hacendística de la Corona de Castilla en la Baja Edad Media, Madrid.

Ladero Quesada, Miguel Ángel (2011), Fiscalidad y poder real en Castilla (12521369), Madrid.

Ladero Quesada, Miguel Ángel (2015), "Lo antiguo y lo nuevo de la investigación sobre fiscalidad y poder político en la Baja Edad Media hispánica”, en Estados 
y mercados financieros en el Occidente cristiano (siglos XIII-XVI), Actas de las XLI Semana de Estudios Medievales de Estella, Pamplona, pp. 13-54.

Ortega Cera, Agatha (2010), "Arrendar el dinero del rey: fraude y estrategias financieras en el Estrado de las Rentas en la Castilla del siglo XV", Anuario de Estudios Medievales, 40-1, pp. 223-249.

Ortego Rico, Pablo (2015), Poder financiero y gestión tributaria en Castilla: los agentes fiscales en Toledo y su reino (1429-1504), Madrid.

Otte, Enrique (1977), Sevilla y sus mercaderes a fines de la Edad Media, Sevilla.

Otte, Enrique (2008), Sevilla, siglo XVI: materiales para su historia económica, Sevilla.

Pulido Bueno, Ildefonso (1993), Almojarifazgos y comercio exterior en Andalucía durante la época mercantilista, 1526-1740, Huelva.

Romero Medina, Raúl (2009), “Almojarifazgo portuense o los derechos de carga y descarga. El cobro de los situados aduaneros del comercio marítimo (14891541)", Revista de Historia del Puerto, 42, pp. 35-62.

Sanz Fuentes, María Josefa y Simó Rodríguez, Isabel (1975), Catálogo de documentos contenidos en los Libros del Cabildo del concejo de Sevilla, Sevilla.

Fecha de recepción del artículo: febrero de 2016

Fecha de aceptación y versión final: mayo de 2016 